\author{
RESEARCH ARTICLE \\ 10.1029/2018JC014334 \\ Key Points: \\ - Long-term trends showed linear \\ increases in Chla and \\ microphytoplankton in the \\ Northern Benguela \\ - Chla and microphytoplankton on \\ the Southern Benguela shelf showed \\ small long-term decreases \\ - Chla and microphytoplankton \\ showed long-term increases in \\ summer but decreased in autumn, \\ winter, and spring on the Agulhas \\ Bank shelf
}

Supporting Information:

- Supporting Information S1

Correspondence to:

T. Lamont,

tarron.lamont@gmail.com

Citation:

Lamont, T., Barlow, R. G., \& Brewin, R. J. W. (2019). Long-term trends in phytoplankton chlorophyll $a$ and size structure in the Benguela Upwelling System. Journal of Geophysical Research: Oceans, 124, 1170-1195. https://doi.org/10.1029/2018JC014334

Received 3 JUL 2018

Accepted 15 JAN 2019

Accepted article online 18 JAN 2019

Published online 22 FEB 2019

\section{Long-Term Trends in Phytoplankton Chlorophyll $a$ and Size Structure in the Benguela Upwelling System}

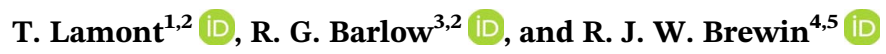 \\ ${ }^{1}$ Oceans \& Coasts Research, Department of Environmental Affairs, Cape Town, South Africa, ${ }^{2}$ Marine Research Institute \\ \& Department of Oceanography, University of Cape Town, Rondebosch, South Africa, ${ }^{3}$ Bayworld Centre for Research \& \\ Education, Constantia, Cape Town, South Africa, ${ }^{4}$ Plymouth Marine Laboratory (PML), Plymouth, UK, ${ }^{5}$ National Centre \\ for Earth Observation, PML, Plymouth, UK
}

Abstract The Benguela Upwelling System (BUS) is among the most productive ecosystems globally, supporting numerous fisheries and ecosystem services in Southern Africa. Sea-viewing Wide Field-of-view Sensor and Moderate-resolution Imaging Spectroradiometer-Aqua chlorophyll $a$ (Chla) concentrations between September 1997 and February 2018 were used to investigate long-term trends in phytoplankton biomass and size structure (microphytoplankton [ $>20 \mu \mathrm{m}]$, nanophytoplankton [2-20 $\mu \mathrm{m}]$, and picophytoplankton $[<2 \mu \mathrm{m}]$ ) in the Northern Benguela, Southern Benguela (SB), and Agulhas Bank (AB) shelf and open ocean regions of the BUS. Trends in upwelling and correlations with Chla and size structure were examined. Increasing Chla and microphytoplankton trends occurred in the Northern Benguela shelf and open ocean, while decreases were evident on the SB shelf in all seasons. In the SB open ocean, small increases occurred during austral winter, with a decrease in spring. On the AB shelf, increases in Chla and microphytoplankton occurred in summer with decreases during the other seasons. Patterns differed in the $\mathrm{AB}$ open ocean, with increases in winter and spring and decreases in summer and autumn. Although $R^{2}$ values indicated that linear trends accounted for a reasonable portion of the variance, and most trends were statistically significant, they showed only small changes on the shelf domains and little to no change in the open ocean. Strong correlations between upwelling, Chla, and the size classes were observed, but distinct seasonal differences occurred in each region. This is the first 20-year analysis of phytoplankton biomass and community structure in the BUS and provides a baseline against which future changes can be monitored.

Plain Language Summary Two satellite ocean color data products were combined and used to examine trends in chlorophyll $a$ and the proportions of microphytoplankton, nanophytoplankton, and picophytoplankton in three subregions of the Benguela Upwelling System, namely, the northern Benguela, southern Benguela, and Agulhas Bank. These trends were related to trends in upwelling-favorable winds and significant correlations were observed but with distinct seasonal differences in each region. Linear trends were mostly significant and accounted for a reasonable portion of the variance, but they showed only small changes on the shelf domains and little to no change in the open ocean regions. This study provides the first 20-year analysis of phytoplankton biomass and community structure in the Benguela Upwelling System and provides a baseline against which future changes can be monitored.

\section{Introduction}

Forming the base of marine food webs, phytoplankton are known to exert a considerable influence on the functioning of marine ecosystems, on biogeochemical cycling, and on several other processes including, for instance, the vertical distribution of solar heating (Chassot et al., 2010; Field et al., 1998; Sathyendranath et al., 2017). In Eastern Boundary Upwelling Ecosystems (EBUE), such as the Benguela Upwelling System (BUS; Figure 1), the role of phytoplankton is critically important, owing to the unique significance of these systems to global fisheries and climate modulation (IPCC, 2014; Pauly \& Christensen, 1995). It is now understood that different phytoplankton groups and types have distinctly different influences on ecosystems and biogeochemical cycles (Cermeño et al., 2006; IOCCG, 2014), thus making it extremely important to gain a better understanding of the structuring of phytoplankton communities in EBUE and their variations.

The BUS differs from other EBUE in that both its northern and southern boundaries are bordered by warmer waters (Hutchings et al., 2009; Shillington et al., 2006). Exchange of certain biota between the
(C)2019. American Geophysical Union. All Rights Reserved. 


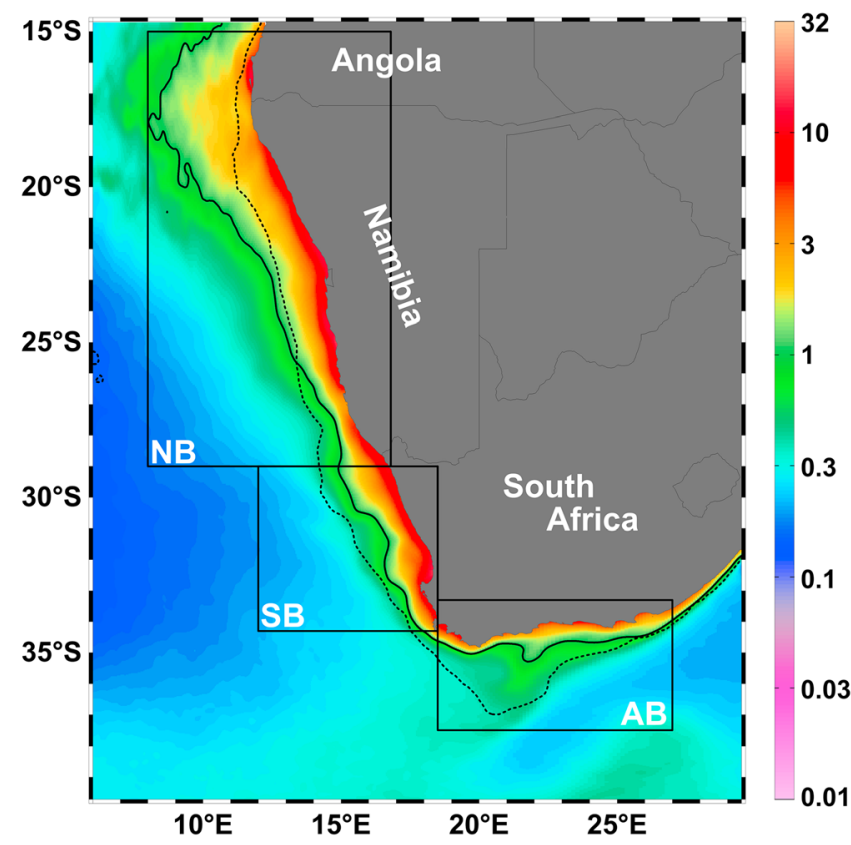

Figure 1. Long-term (2002-2017) mean MODIS-Aqua chlorophyll $a$ (mg/ $\mathrm{m}^{3}$ ) in the Benguela Upwelling System with demarcated regions. (NB [15$\left.\left.29^{\circ} \mathrm{S} ; 8-16.8^{\circ} \mathrm{E}\right], \mathrm{SB}\left[29-34.3^{\circ} \mathrm{S} ; 12-18.5^{\circ} \mathrm{E}\right], \mathrm{AB}\left[33.3-37.5^{\circ} \mathrm{S} ; 18.5-27^{\circ} \mathrm{E}\right]\right)$. Black solid contour indicates the $1 \mathrm{mg} / \mathrm{m}^{3}$ isoline, and the dotted black contour indicates the GEBCO 1,000-m isobath (Becker et al., 2009). In each region, the area between the coast and the 1,000-m isobath (dotted black contour) is referred to as the shelf domain, while the area seaward of the $1,000-\mathrm{m}$ isobath is referred to as the open ocean domain. $\mathrm{NB}=$ Northern Benguela; $\mathrm{SB}=$ Southern Benguela; $\mathrm{AB}=$ Agulhas Bank. northern and southern subsystems is said to be curbed by perennial upwelling at Lüderitz $\left(27.5^{\circ} \mathrm{S}\right)$ which is believed to form an environmental barrier (Hutchings et al., 2009; Lett et al., 2007; Verheye et al., 2016). These regions exhibit differences in their primary modes of variability, suggesting contrasting forcing mechanisms between the two subsystems (Hutchings et al., 2009). While the Northern Benguela (NB) experiences perennial upwelling, the Southern Benguela (SB) exhibits strongly seasonal upwelling with maxima in austral spring and summer (Hutchings et al., 2009; Shillington et al., 2006). Benguela Niños, analogous to the Pacific El Niño, are known to strongly influence the atmospheric circulation over the NB system but have little to no impact on the SB (Florenchie et al., 2004; Rouault et al., 2003). Detailed reviews of the influence of large-scale modes of variability in these systems have been presented by Shillington et al. (2006) and Reason et al. (2006), among others. South of South Africa, the Agulhas Bank (AB; Figure 1) is ecologically and economically important since it comprises the major spawning grounds for numerous fish species which recruit to the west coast (Hutchings et al., 2009; Kirkman et al., 2016). Large-scale climate modes, such as El Niño Southern Oscillation and the Antarctic Annual Oscillation, are known to impact these regions, but their effects are not always clearly discernible (Reason et al., 2006; Rouault et al., 2010). El Niño Southern Oscillation has been observed to be significantly and positively correlated with sea surface temperature (SST) in the SB and AB regions from February to May, with El Niño conditions enhancing upwelling and La Niña conditions suppressing upwelling along the coast (Rouault et al., 2010). In contrast, correlations between SST and the Antarctic Annual Oscillation were less clear (Pohl et al., 2010; Rouault et al., 2010).

Long-term data sets are an essential requirement to adequately monitor and understand changes in marine ecosystems. To date, ocean color measurements provide the longest and most spatially and temporally coherent observations of chlorophyll $a$ (Chla) concentrations in most parts of the global ocean, and these have been used in numerous studies to investigate spatial variations as well as seasonal, interannual, and longer-term changes in phytoplankton biomass. Numerous regions of the global ocean have been reported to show long-term warming trends (Belkin, 2009), and previous studies have shown an inverse relationship between SST and Chla in many subtropical regions, with Chla showing decreases as temperatures increase and vice versa (Behrenfeld et al., 2006; Martinez et al., 2009; Siegel et al., 2013). It has been proposed that at high latitudes, where phytoplankton are often light-limited, they will benefit from ocean warming due to decreased vertical mixing enhancing the levels of solar radiation in the upper mixed layer and promoting an increase in Chla (Behrenfeld et al., 2006; Doney, 2006). In contrast, at lower latitudes, where phytoplankton are often nutrient-limited, a warmer ocean would result in decreased Chla as a result of stronger stratification and reduced vertical nutrient fluxes (Boyce et al., 2010; Chavez et al., 2011; Gregg et al., 2005; Polovina et al., 2008). Furthermore, at these low latitudes, the structure of phytoplankton communities is expected to shift from large species dominance to smaller nanophytoplankton and picophytoplankton as warming occurs and subtropical gyres expand (Henson et al., 2013).

In the BUS, recent studies have shown that despite strong interannual and decadal variability, a significant linear increase in upwelling-favorable winds suggestive of coastal cooling has occurred on the AB (Lamont, García-Reyes, et al., 2018; Rouault et al., 2010; Tim et al., 2015). While there was a tendency toward increased upwelling in the SB and less upwelling in the NB in recent years, the linear trends in these regions were not significant (Jarre et al., 2015; Lamont, García-Reyes, et al., 2018, Tim et al., 2015). Although there have been several studies that have examined the seasonal and longer-term changes in satellite Chla (Demarcq, 2009; Demarcq et al., 2003, 2007; Jarre et al., 2015; Verheye et al., 2016), those investigating variations in satellite-derived phytoplankton size structure have been limited to describing large-scale spatial 
differences and the seasonal cycle (Hirata et al., 2009; Lamont, Brewin, et al., 2018). In this study, we use the Sea-viewing Wide Field-of-view Sensor (SeaWiFS) and Moderate-resolution Imaging Spectroradiometer (MODIS)-Aqua satellite data sets to examine the long-term temporal variations in the seasonal mean Chla and phytoplankton size structure in various subregions of the BUS. Specifically, we investigated (1) the differences between the SeaWiFS and MODIS-Aqua data sets, and whether a single contiguous time series could be derived from these data sets in the BUS, and (2) if there was a significant linear trend in Chla and/or the proportions of microphytoplankton, nanophytoplankton, and picophytoplankton over the period between 1997 and 2018 during austral summer, autumn, winter, and spring, and (3) if there was a significant relationship between the trends in upwelling and the trends in Chla and the size structure.

\section{Data and Methods}

\subsection{Phytoplankton Size Class Model}

A global abundance-based Phytoplankton Size Class model was developed to estimate the Chla concentrations of three phytoplankton size classes (microphytoplankton [ $>20 \mu \mathrm{m}]$, nanophytoplankton [2-20 $\mu \mathrm{m}]$, and picophytoplankton $[<2 \mu \mathrm{m}]$ ) as a function of the total Chla concentration ( $C$; Brewin et al., 2010). The model was parameterized by coefficients determined from the relationship between High Performance Liquid Chromatography (HPLC)-derived biomarker pigments and total Chla (Uitz et al., 2006), with additional refinements according to Brewin et al. (2010) and Devred et al. (2011). Application and validation of the model with independent in situ data has been conducted in various ocean regions (Brewin et al., 2010, 2012; Brewin, Raitsos, et al., 2015, Brewin, Sathyendranath, et al., 2015; Brito et al., 2015; Ward, 2015), and a detailed description of the global model and its parameterization can be found in Brewin, Sathyendranath, et al. (2015).

For application to the BUS, the parameterization of the global model was refined using in situ HPLC data from the southern African marine environment, as described by Lamont, Brewin, et al. (2018). Samples were matched in time and space to daily level 3 MODIS-Aqua Chla (v2014.0) data according to Bailey and Werdell (2006). A total of 374 samples was used to refine the parameterization of the model, and a standard, nonlinear, least-squares method with relative weighting was used to retrieve model parameters, while 33 satellite matchups were used for independent validation (Brewin, Sathyendranath, et al., 2015; Lamont, Brewin, et al., 2018). The refined model was found to have significantly higher slopes in model parameters, indicating a higher contribution of small cells at low total Chla concentrations (Lamont, Brewin, et al., 2018), when compared to previous global and Atlantic studies (Brewin et al., 2010, Brewin, Sathyendranath, et al., 2015), thus justifying the regional refinement of model parameters.

Picophytoplankton Chla $\left(C_{p}\right)$ was determined using zeaxanthin, total chlorophyll $b$, and a portion of the $19^{\prime}$ hexanoyloxyfucoxanthin pigment at total Chla concentrations $\leq 0.08 \mathrm{mg} / \mathrm{m}^{3}$. Nanophytoplankton Chla $\left(C_{n}\right)$ was computed from 19'-hexanoyloxyfucoxanthin, 19'-butanoyloxyfucoxanthin, alloxanthin, and by assigning some of the fucoxanthin pigment to the nanophytoplankton pool, in line with Devred et al. (2011). Microphytoplankton Chla $\left(C_{m}\right)$ was computed using the remaining fucoxanthin (attributed to the microphytoplankton size class) and peridinin (Brewin, Sathyendranath, et al., 2015; Devred et al., 2011). Further details of the refinement, parameterization, and application of the retuned model to the Southern African marine environment are described in Lamont, Brewin, et al. (2018) and Lamont, Barlow, et al. (2018).

\subsection{Satellite Data Analysis}

Standard monthly averaged SeaWiFS (NASA Goddard Space Flight Center et al., 2018a) and MODIS-Aqua Chla concentrations (NASA Goddard Space Flight Center et al., 2018b), with a spatial resolution of $9 \mathrm{~km}$, for the 1997-2018 period, were used to generate seasonal means of Chla and the fractional contributions of microphytoplankton, nanophytoplankton, and picophytoplankton in three regions of the BUS, namely, the $\mathrm{NB}, \mathrm{SB}$, and $\mathrm{AB}$ (Figure 1). These regions were delineated on the basis of spatial variations in physical driving forces, biological responses, and trophic structuring (Hutchings et al., 2009; Kirkman et al., 2016). SeaWiFS data for the period from September 1997 to December 2007 were used, while MODIS-Aqua data covered the period from July 2002 to February 2018. In contrast to Lamont, Brewin, et al. (2018), who used the $1 \mathrm{mg} / \mathrm{m}^{3}$ Chla contour, in this study the GEBCO 1,000-m isobath (Becker et al., 2009) was used to separate between the higher biomass shelf and lower biomass open ocean areas in each of these regions (Figure 1). 
Although Chla concentrations above $1 \mathrm{mg} / \mathrm{m}^{3}$ extend beyond the 1,000-m contour in the central and northern parts of the NB shelf region (Figure 1; Demarcq et al., 2007; Lamont, Brewin, et al., 2018), using the $1,000-\mathrm{m}$ isobath to separate between shelf and open ocean regions ensured that areas selected for averaging were consistent and comparable between the SeaWiFS and MODIS-Aqua data sets (Figure 1). Similar to Lamont, Brewin, et al. (2018), in each of the shelf and open ocean regions, seasonal means were computed by averaging the data over a 3-month period for each season, defined as austral summer (December, January, and February), austral autumn (March, April, and May), austral winter (June, July, and August), and austral spring (September, October, and November). Austral summer means have been labeled as the year in which the season starts (e.g., austral summer 1997 includes the December 1997, January 1998, and February 1998 monthly data).

The relationship between the measured Chla and the fractional contributions of microphytoplankton, nanophytoplankton, and picophytoplankton for the two platforms (SeaWiFS and MODIS-Aqua) were explored. As shown in Figures 2 and 3, with the exception of some seasons in the NB region, there was a strong linear relationship between the Chla and the fractional contributions obtained from the two platforms. This indicated the potential to reconstruct these time series from the MODIS-Aqua platform back in time, so as to obtain a single coherent data set from which the long-term trends and interannual variations could be described. In this study the time series reconstruction was done within the framework of a Generalized Linear Model (GLM), using MODIS-Aqua as the reference data set since it composed of more years of data than SeaWiFS. Although some regional studies have shown better performance of SeaWiFS than MODISAqua when compared to in situ data (Djavidnia et al., 2010; Werdell et al., 2009), when using the SeaWiFS data set as a reference, reconstructed Chla values were overall lower (results not shown), but the pattern of variability was the same as that obtained when using the MODIS-Aqua data set as a reference. It is acknowledged that more sophisticated methods exist for combining these satellite time series (Maritorena \& Siegel, 2005; Mélin \& Sclep, 2015; Signorini et al., 2015) and that merged time series are available (Grant et al., 2017). However, the latest merged data (v3.1) are currently only available until the end of 2016 and are based on older reprocessing versions of the SeaWiFS and MODIS-Aqua data sets (http://www. esa-oceancolour-cci.org/), acknowledging that future versions will incorporate these updated reprocessings.

Analysis of Variance (ANOVA) tests were conducted to determine the influence of three independent categorical factors (platform, year, and season) and their interactive effects on the Chla concentration and the fractional contributions of microphytoplankton, nanophytoplankton, and picophytoplankton in each of the regions. Analyses for Chla were conducted in $\log _{10}$ space, while those for the fractional contributions were conducted in linear space. Factors identified as significant in the ANOVA were then entered into the GLM, assuming a Gaussian distribution. The specific form of the GLM used to reconstruct the time series is given below:

$$
\text { Chla }_{i y s p}=\alpha+\beta_{i y} Y_{i}+\beta_{i s} S_{i}+\beta_{i p} P_{i}+\beta_{i s p} S_{i}: P_{i}+\varepsilon_{i}
$$

where Chla ${ }_{i y s p}$ is the Chla concentration measured by the platform $(P)$ in a given season $(S)$ and year $(Y), \alpha$ is the intercept, $\beta_{i}$ is the modeled coefficient estimate corresponding to each categorical factor (i.e., platform, season, and year), $S_{i}: P_{i}$ is the season and platform interaction, and $\varepsilon_{i}$ is the error term at time $i$. This same form of GLM was used to reconstruct the time series of fractional contributions of microphytoplankton, nanophytoplankton, and picophytoplankton.

Examination of model diagnostic plots (fitted values vs. residuals and quantile-quantile plots) indicated no violation of model assumptions and good performance of the GLM, and the predict function in R v3.4.4 (R Core Team, 2018) was then used to reconstruct the time series of Chla (Lamont et al., 2019a, 2019b, 2019c) and the fractional contributions of microphytoplankton (Lamont et al., 2019d, 2019e, 2019f), nanophytoplankton (Lamont et al., 2019g, 2019h, 2019i), and picophytoplankton (Lamont et al., 2019j, 2019k, 2019l), from the fitted GLM. The reconstructed (predicted) Chla time series was obtained as follows:

$$
\text { Chla } i y s p=\alpha+\widehat{Y_{i}}+\widehat{S_{i}}+\widehat{P_{\text {iref }}}+\widehat{S_{i}}: \widehat{P}_{i},
$$

where $C h l a_{i y s p}$ is the reconstructed (predicted) Chla concentration for a given year, season, and platform, $\widehat{Y}_{i}$ is the estimated year effect, $\widehat{S_{i}}$ is the estimated season effect, $\widehat{P_{\text {iref }}}$ is the estimated platform effect for the reference platform (in this case, MODIS-Aqua), and $\widehat{S}_{i}: \widehat{P}_{i}$ is the estimated season and platform interaction at 

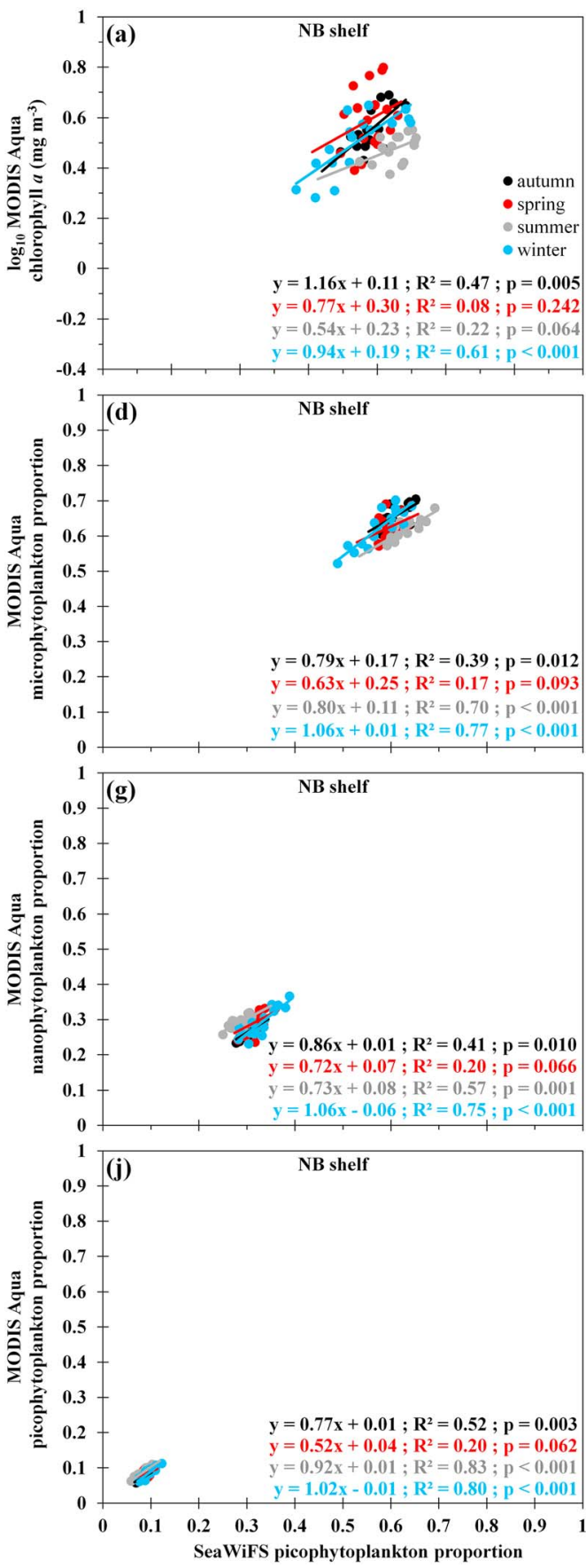
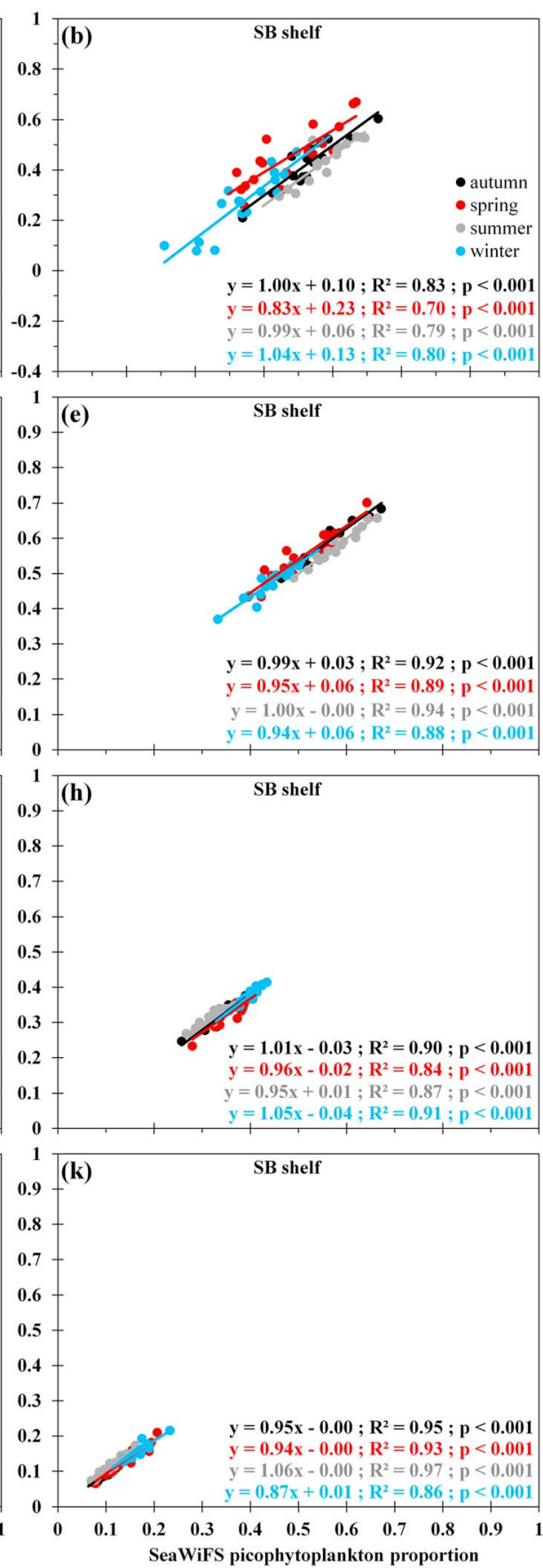
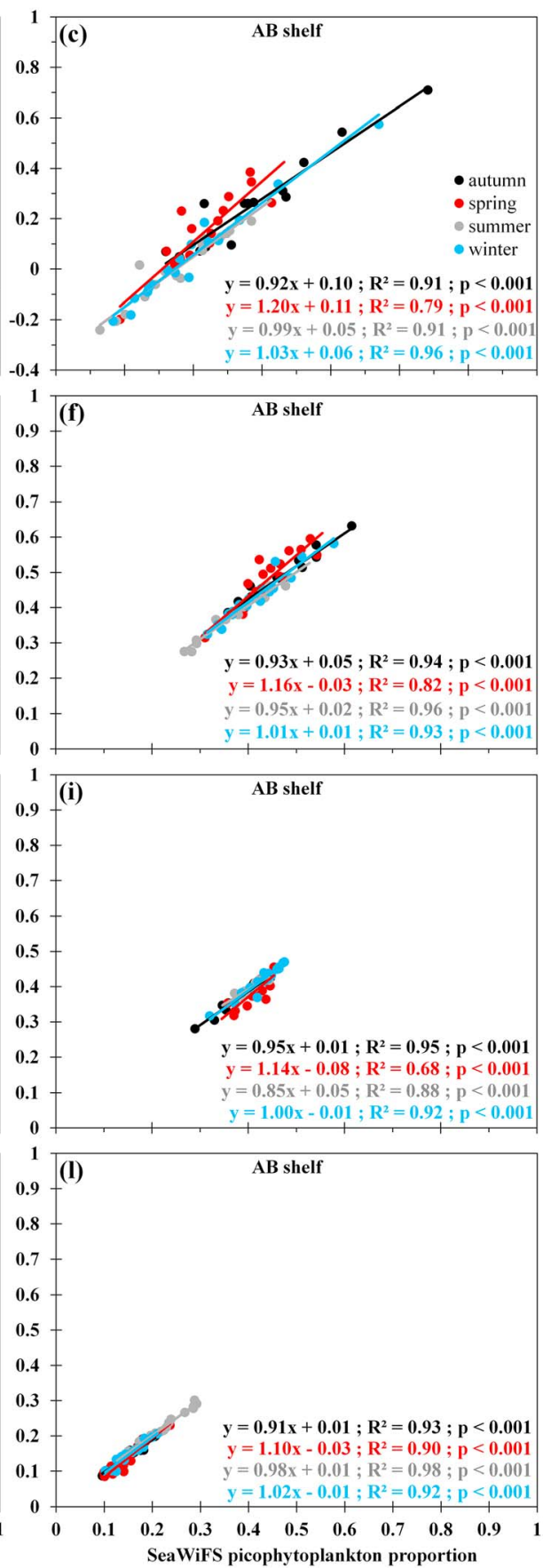

Figure 2. Relationship between monthly values (July 2002 to December 2007) of SeaWiFS and MODIS-Aqua (a-c) chlorophyll $a$ (mg/m³) and the fractional contribution of (d-f) microphytoplankton, (g-i) nanophytoplankton, and (j-l) picophytoplankton, in the Northern Benguela (NB), Southern Benguela (SB), and Agulhas Bank (AB) shelf regions.

time $i$. The same formulation was used to reconstruct (predict) the fractional contributions of microphytoplankton, nanophytoplankton, and picophytoplankton. The reconstructed (predicted) time series were then used to examine the long-term trends of Chla (Lamont et al., 2019a, 2019b, 2019c) and the fractional contributions of microphytoplankton, nanophytoplankton, and picophytoplankton (Lamont et al., 2019d, 2019e, 2019f, 2019g, 2019h, 2019i, 2019j, 2019k, 2019l) in each of the shelf and open ocean regions of the BUS during austral summer, autumn, winter, and spring. 

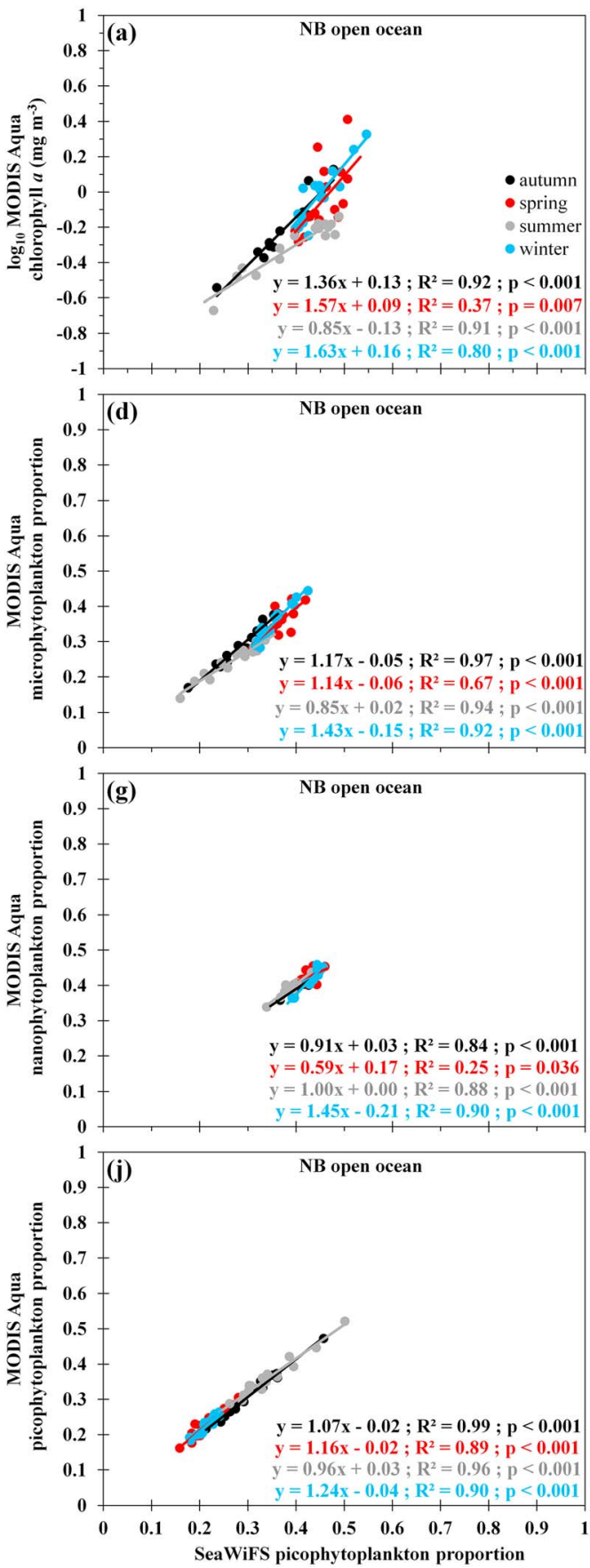
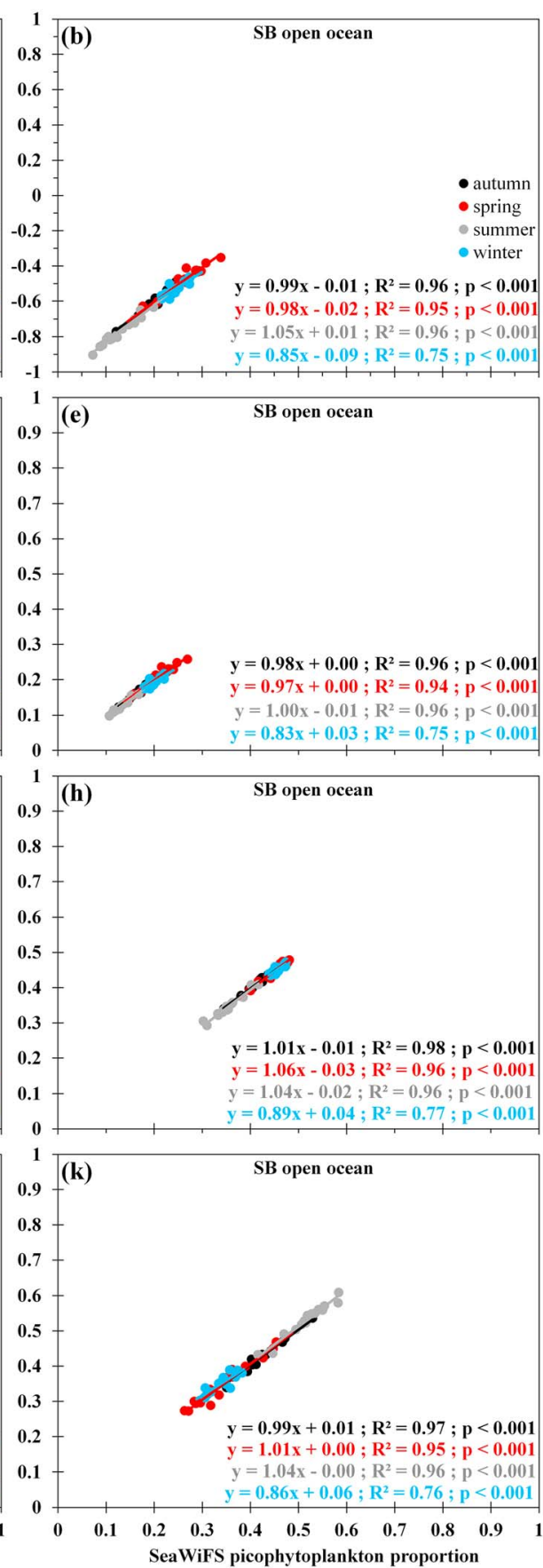
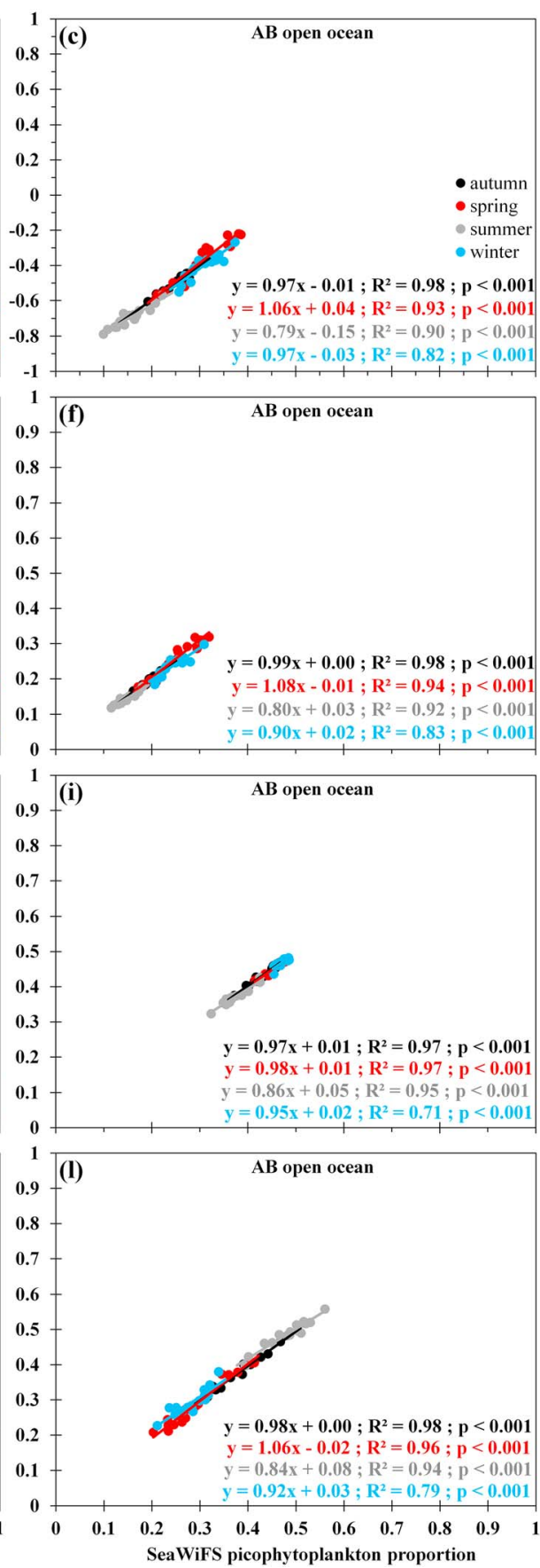

Figure 3. Relationship between monthly values (July 2002 to December 2007) of SeaWiFS and MODIS-Aqua (a-c) chlorophyll $a$ (mg/m ${ }^{3}$ ) and the fractional contribution of (d-f) microphytoplankton, (g-i) nanophytoplankton, and (j-l) picophytoplankton, in the Northern Benguela (NB), Southern Benguela (SB), and Agulhas Bank $(\mathrm{AB})$ open ocean regions.

Daily averaged National Centers for Environmental Prediction-Department of Energy (NCEP-DOE) Reanalysis 2 wind vectors (Kanamitsu et al., 2002) were used to compute daily values of cumulative Ekman transport (cubic meters per second) per $100 \mathrm{~m}$ of coastline, as an index of upwelling in the shelf regions, according to the procedures detailed in Lamont, García-Reyes, et al. (2018). Monthly values of the total cumulative upwelling were then computed by summing all daily cumulative offshore Ekman transport, and seasonal means were calculated by averaging data over a 3-month period (Lamont et al., 2019m, 2019n, 2019o), as described above. Seasonal means of the total cumulative upwelling (Lamont et al., 
2019m, 2019n, 2019o), as well as the Chla (Lamont et al., 2019a, 2019b, 2019c) and fractional contributions of microphytoplankton, nanophytoplankton, and picophytoplankton (Lamont et al., 2019d, 2019e, 2019f, 2019g, 2019h, 2019i, 2019j, 2019k, 2019l), in the shelf regions were low-pass filtered to remove interannual and decadal variability, and the trends in the time series were determined as the slope of the linear regression. Spectral analysis of total cumulative upwelling by Lamont, García-Reyes, et al., (2018; see their supplementary material) showed energy peaks at periods of less than 10 years for the NB and SB systems, but an energy peak at 14.77 years was observed in the AB region. Thus, two low-pass filters, one with a cutoff period of 10 years and the other with a cutoff period of 15 years, were applied to the data in the current study. Both filters yielded similar results for all seasons in all shelf regions, although the 15-year filter showed slightly higher $R^{2}$ and $p$ values. In addition, these filters were applied to the anomalies (computed by subtracting the time series mean) of each time series, but the estimated trends were the same for both the absolute values as well as the anomalies of each time series. Thus, we have included only the results for the low-pass filter, with a 15-year cutoff period, applied to the absolute values of each time series.

\section{Results}

\subsection{Chla and Size Structure Data Set Comparisons}

Figures 4-6 illustrate the seasonal mean Chla for SeaWiFS and MODIS-Aqua in the NB, SB, and AB regions, respectively. In all shelf regions, SeaWiFS Chla was consistently lower than MODIS-Aqua Chla, with the largest differences observed in the NB and the smallest in the AB region. A similar seasonal pattern was found in each of the shelf regions, with differences between platforms being the largest in austral spring (up to $2.17 \mathrm{mg} / \mathrm{m}^{3}$ in the $\mathrm{NB}, 1.28 \mathrm{mg} / \mathrm{m}^{3}$ in the $\mathrm{SB}$, and $0.55 \mathrm{mg} / \mathrm{m}^{3}$ in the $\mathrm{AB}$ region) and the smallest during austral summer (up to $0.28 \mathrm{mg} / \mathrm{m}^{3}$ in the $\mathrm{NB}, 0.62 \mathrm{mg} / \mathrm{m}^{3}$ in the $\mathrm{SB}$, and $0.21 \mathrm{mg} / \mathrm{m}^{3}$ in the AB region; Figures 46). In contrast, the differences between SeaWiFS and MODIS-Aqua were considerably smaller in the open ocean regions of the NB (up to $0.55 \mathrm{mg} / \mathrm{m}^{3}$ ), $\mathrm{SB}$ (up to $0.02 \mathrm{mg} / \mathrm{m}^{3}$ ), and AB (up to $0.06 \mathrm{mg} / \mathrm{m}^{3}$ ). Similar to the shelf regions, the open ocean domains of the SB and $\mathrm{AB}$ showed the largest differences in austral spring, while the NB had the largest differences in both austral autumn and spring. In contrast to the shelf regions, the SB open ocean region showed the smallest differences in austral winter (Figure 5), while the NB and $\mathrm{AB}$ open ocean regions had the smallest differences in austral summer and winter (Figures 4 and 6).

Despite the systematic differences between SeaWiFS than MODIS-Aqua Chla in each of the regions (Figures 4-6), regressions between $\log _{10}$ monthly values of SeaWiFS and MODIS-Aqua during the overlapping period (July 2002 to December 2007) showed clear, strong, and statistically significant linear relationships during all seasons in the shelf and open ocean areas of the SB and AB regions, indicating good agreement between these data sets (Figures $2 \mathrm{~b}$ and $2 \mathrm{c}$ and $3 \mathrm{~b}$ and $3 \mathrm{c}$ ). This good agreement is also clearly evident in Figures 5 and 6, with both SeaWiFS and MODIS-Aqua Chla showing very similar patterns of variability between 2002 and 2007, despite the differences in the absolute Chla values. Overall, the relationships were stronger in the open ocean than in the shelf regions, and there were some small seasonal differences in the slopes of these relationships in the shelf areas, particularly during austral spring (Figures 2 and 3). The weakest relationships between SeaWiFS and MODIS-Aqua were observed in spring and summer in the NB region (Figures $2 \mathrm{a}$ and $3 \mathrm{a}$ ).

ANOVA tests conducted to determine the influence of three independent factors (platform [i.e., SeaWiFS or MODIS-Aqua], year, and season) and their interactive effects on the monthly mean Chla concentrations in each of the regions indicated that the effects of platform, year, and season on Chla were all significant in the NB and SB shelf regions, while only platform and season were significant in the AB shelf region (supporting information Table S1). In addition, in the NB shelf region, the interaction between platform and season was also significant, indicating differences in the Chla values between SeaWiFS and MODIS-Aqua for a given season. This is also evident from the seasonal regressions for the NB shelf region (Figures $2 \mathrm{a}$ and $3 \mathrm{a}$ ). In contrast, in the SB and $\mathrm{AB}$ shelf regions, the interaction between year and season was significant, reflecting interannual differences in these regions for a given season (Table S1). In the open ocean domain, the effects of year and season were significant in all regions (Table S2). In the NB open ocean region, the interactive effects of platform and season, as well as year and season, were also significant, while in the SB open ocean region, the interactive effect of year and season was significant (Table S2). Importantly, in all the shelf and open ocean regions (Tables S1 and S2), the interaction between platform, year, and season was not 

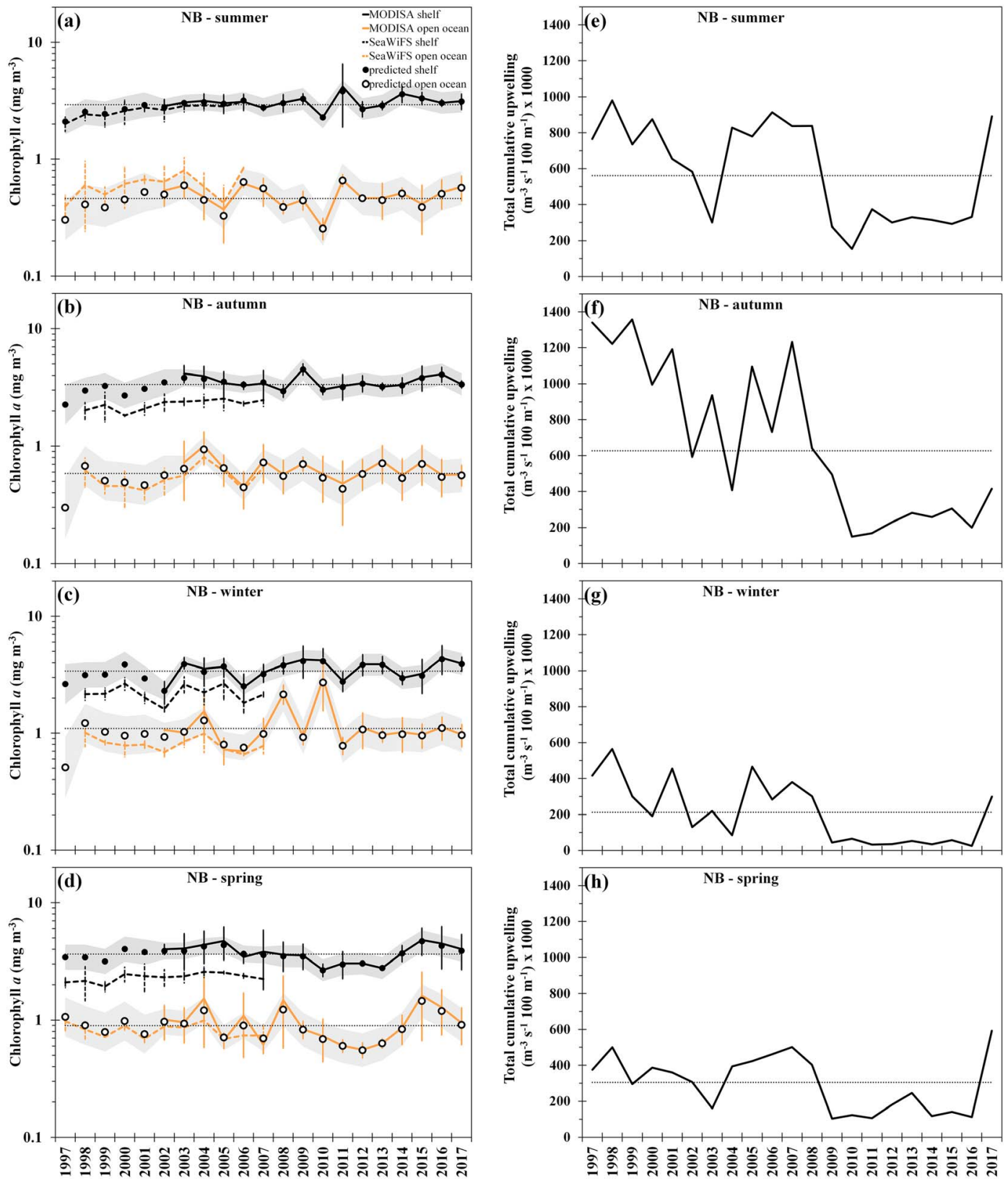

Figure 4. Seasonal mean chlorophyll $a\left(\mathrm{mg} / \mathrm{m}^{3}\right)$ for SeaWiFS and MODIS-Aqua in the Northern Benguela (NB) shelf and open ocean regions during austral (a) summer, (b) autumn, (c) winter, and (d) spring and seasonal mean total cumulative upwelling $\left(\mathrm{m}^{-3} \cdot \mathrm{s}^{-1} \cdot 100 \mathrm{~m}^{-1}\right.$ ) during austral (e) summer, (f) autumn, (g) winter, and (h) spring, for the period 1997 to 2017. Solid and dashed black and orange vertical lines indicate the standard deviation for MODIS-Aqua and SeaWiFS, respectively. Reconstructed (predicted) seasonal mean chlorophyll $a$ in the shelf and open ocean regions are indicated as black and white dots, respectively, and the $95 \%$ confidence interval for the predicted values are indicated as light gray shaded areas. Horizontal dotted black lines indicate the time series mean reconstructed (predicted) chlorophyll $a$ and total cumulative upwelling in each season.

significant, indicating that there were no significant differences between the monthly values of SeaWiFS and MODIS-Aqua in these regions. These ANOVA results confirm the regression results (Figures 2a-2c and 3a-3c) and the patterns observed in Figures 4-6. However, some caution is warranted when comparing these data sets in NB region, particularly during austral summer and spring, since these seasons showed the largest differences between the platforms (Figures 2a and 3a).

ANOVA tests on the size classes indicated similar results to the Chla, with the same factors showing a significant effect on the proportions in each of the regions (Tables S3-S8). Both data sets showed similar 

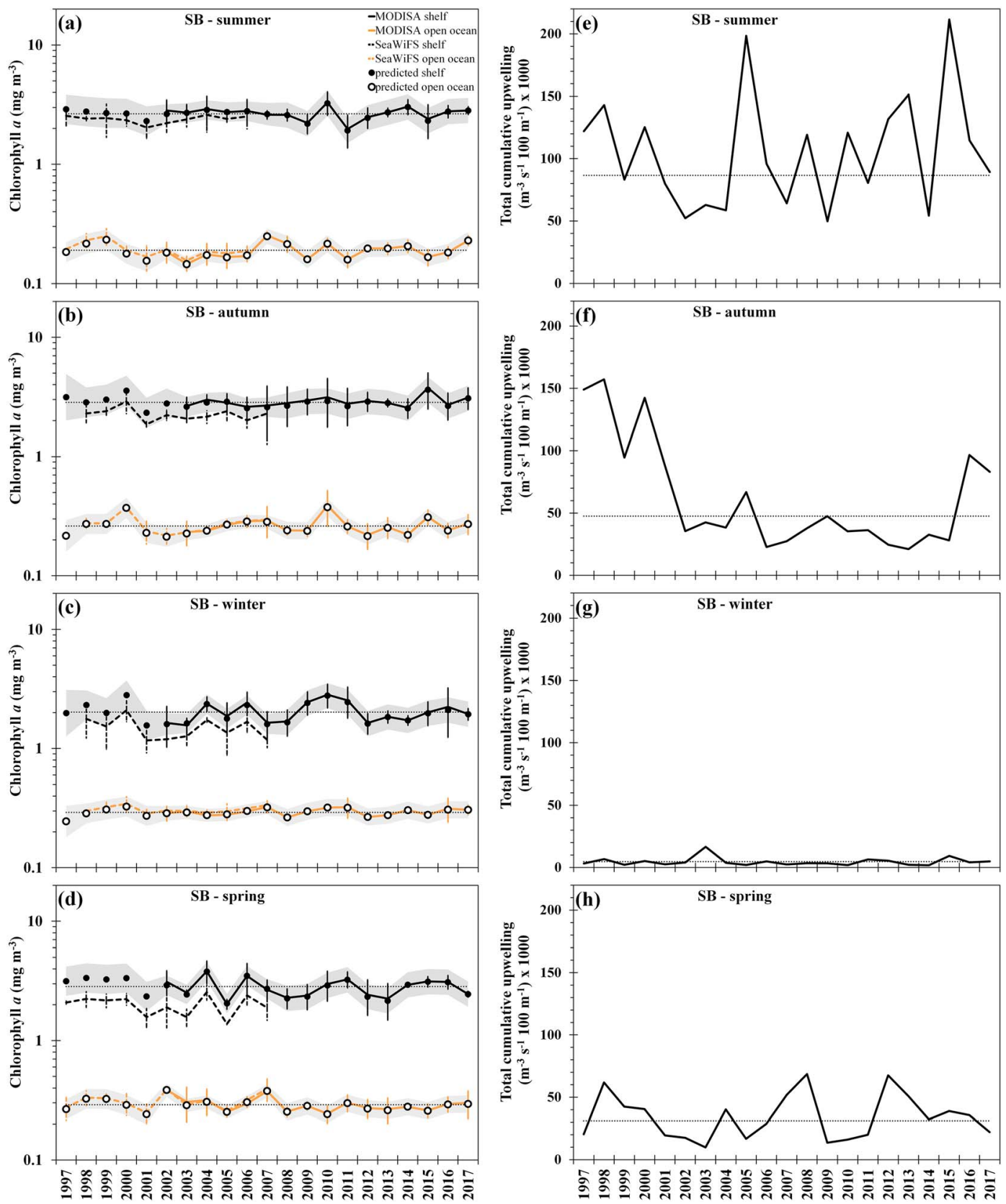

Figure 5. Seasonal mean chlorophyll $a\left(\mathrm{mg} / \mathrm{m}^{3}\right)$ for SeaWiFS and MODIS-Aqua in the Southern Benguela (SB) shelf and open ocean regions during austral (a) summer, (b) autumn, (c) winter, and (d) spring and seasonal mean total cumulative upwelling $\left(\mathrm{m}^{-3} \cdot \mathrm{s}^{-1} \cdot 100 \mathrm{~m}^{-1}\right.$ ) during austral (e) summer, (f) autumn, (g) winter, and (h) spring, for the period 1997 to 2017. Solid and dashed black and orange vertical lines indicate the standard deviation for MODIS-Aqua and SeaWiFS, respectively. Reconstructed (predicted) seasonal mean chlorophyll $a$ in the shelf and open ocean regions are indicated as black and white dots, respectively, and the $95 \%$ confidence interval for the predicted values are indicated as light gray shaded areas. Horizontal dotted black lines indicate the time series mean reconstructed (predicted) chlorophyll $a$ and total cumulative upwelling in each season.

proportions of each size class, and overall, there was a much closer match between SeaWiFS and MODISAqua for the fractional contributions of microphytoplankton, nanophytoplankton, and picophytoplankton during all seasons in the shelf and open ocean regions of the NB, SB, and AB (Figures 7-12), than was observed for Chla (Figures 4-6). This is also evident in the regressions of the various size classes between the two platforms (Figures $2 \mathrm{~d}-2 \mathrm{l}$ and $3 \mathrm{~d}-3 \mathrm{l}$ ). In the shelf regions, microphytoplankton fractions showed very similar differences between the platforms to those observed for Chla, likely due to the larger contribution of the microphytoplankton to the total Chla. In each of the shelf and open ocean regions, the 

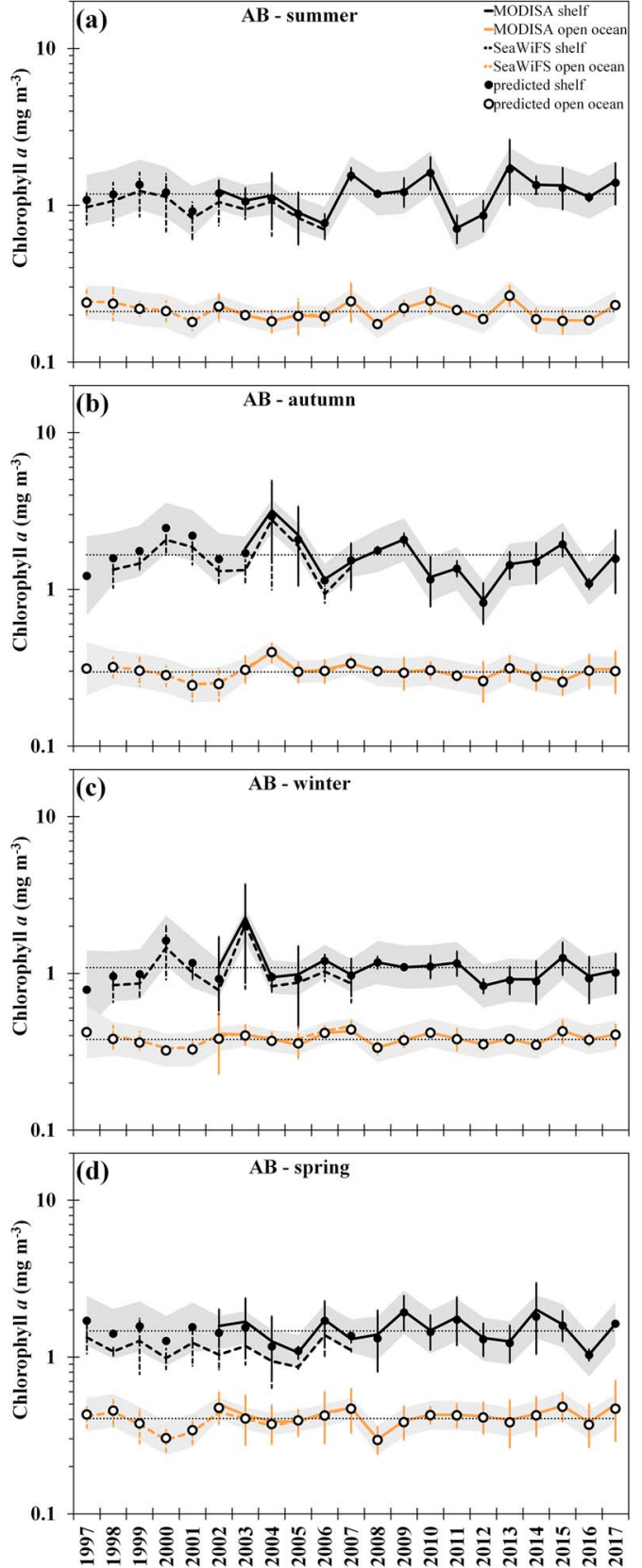
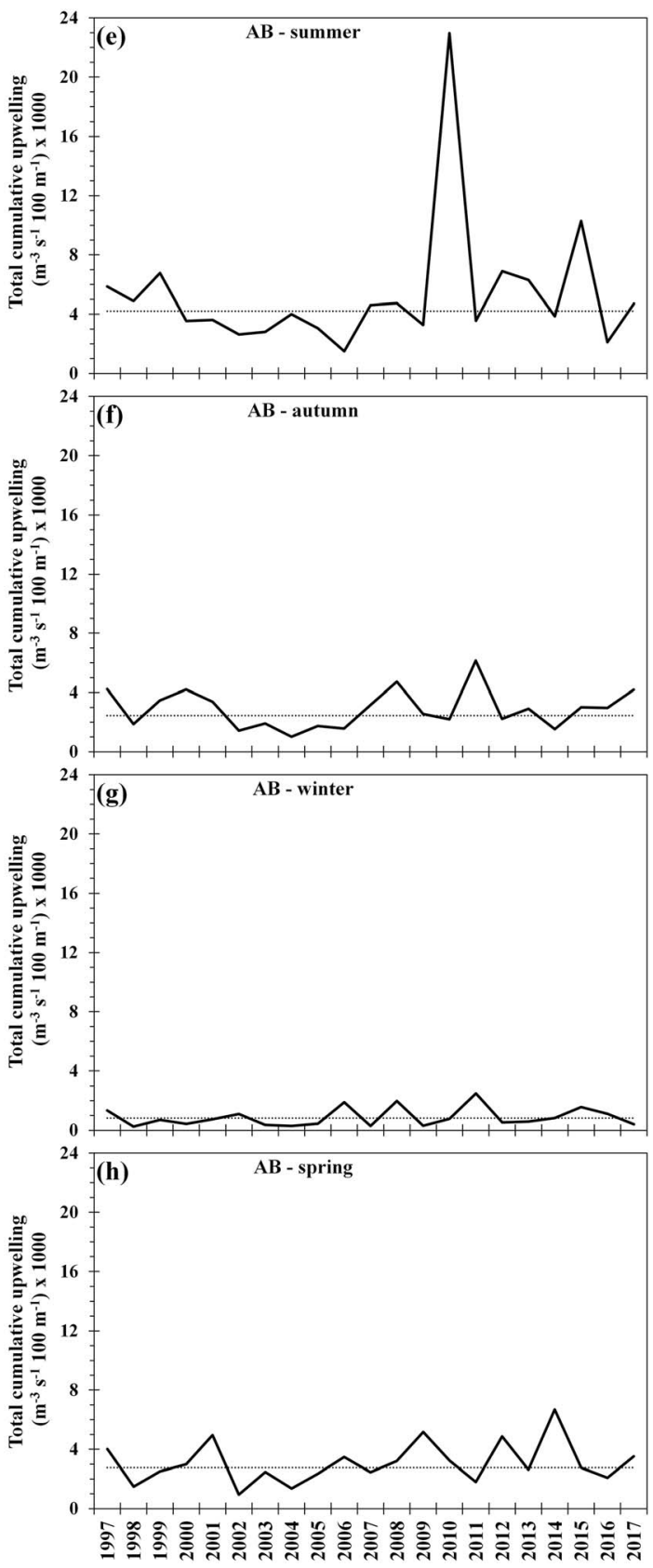

Figure 6. Seasonal mean chlorophyll $a\left(\mathrm{mg} / \mathrm{m}^{3}\right)$ for SeaWiFS and MODIS-Aqua in the Agulhas Bank (AB) shelf and open ocean regions during austral (a) summer, (b) autumn, (c) winter, and (d) spring and seasonal mean total cumulative upwelling $\left(\mathrm{m}^{-3} \cdot \mathrm{s}^{-1} \cdot 100 \mathrm{~m}^{-1}\right.$ ) during austral (e) summer, (f) autumn, (g) winter, and (h) spring, for the period 1997 to 2017. Solid and dashed black and orange vertical lines indicate the standard deviation for MODIS-Aqua and SeaWiFS,

respectively. Reconstructed (predicted) seasonal mean chlorophyll $a$ in the shelf and open ocean regions are indicated as black and white dots, respectively, and the 95\% confidence interval for the predicted values are indicated as light gray shaded areas. Horizontal dotted black lines indicate the time series mean reconstructed (predicted) chlorophyll $a$ and total cumulative upwelling in each season.

reconstructed (predicted) Chla values (Figures 4-6), as well as the predicted proportions of microphytoplankton, nanophytoplankton, and picophytoplankton (Figures 7-12), are higher than the original SeaWiFS values between 1997 and 2002. As explained earlier, this was due to the fact that the MODIS-Aqua data set was used as a reference for reconstructing the values during the SeaWiFS period. Most importantly, all the reconstructed (predicted) values illustrated the same pattern of variability as the SeaWiFS values between 1997 and 2002 and the MODIS-Aqua values between 2002 and 2017, thus giving 
credence to the use of these reconstructed values for determining the long-term trends and interannual variations in each of the regions.

\subsection{Chla, Size Structure, and Upwelling Variations}

In the NB shelf region, the highest seasonal mean Chla values were observed in austral autumn, winter, and spring, while the lowest were noted in austral summer, and considerable interannual changes were notable during all seasons (Figures 4a-4d). Standard deviations were higher in winter and spring, indicating greater variability in these months than during summer and autumn. An increasing trend in Chla from 1997 to 2017 was evident during summer, autumn, and winter. In contrast, during spring, Chla showed increasing values from 1997 to 2005, followed by a decreasing pattern until 2013, and higher values in recent years, suggesting decadal-scale changes in Chla. Although upwelling occurred throughout the year on the NB shelf, seasonal variation was evident, with more upwelling occurring in summer and autumn and less during winter and spring (Figures 4e-4h). During the early part of the time series, upwelling was substantially greater, exceeding the long-term mean during most years. In contrast, substantially lower values were observed between 2009 and 2016 (Figures 4e-4h). While upwelling has increased above the long-term mean during summer, winter, and spring of 2017, the upwelling during autumn 2017 was still well below the long-term mean. Linear regressions indicated that the decreasing upwelling trends were significant during all seasons (Table 1), while those for Chla in the NB shelf and open ocean domains were positive and significant in summer, autumn, and winter only (Tables 1 and S9). Notably, Chla trends during all seasons were very small, with the largest increase $\left(0.042 \pm 0.006 \mathrm{mg} \cdot \mathrm{m}^{-3} \cdot \mathrm{year}^{-1}\right)$ observed during autumn in the shelf region (Table 1). Chla trends in the NB open ocean domain were even smaller (Table S9).

Seasonal mean Chla and standard deviations in SB and AB shelf regions were the highest during spring and autumn (Figures 5 and 6). Chla values in these open ocean domains were elevated throughout autumn, winter, and spring and showed much less variation throughout the 1997-2017 period (Figures 5 and 6), in contrast to the NB open ocean region where substantial interannual differences were observed in some years, especially during winter and spring (Figure 4). A similar seasonal pattern was observed for upwelling in the $\mathrm{SB}$ and $\mathrm{AB}$ shelf regions, with upwelling being strongest in summer and weakest in winter, and both regions exhibited substantial interannual variability (Figures 5 and 6). In the SB shelf region, upwelling showed an increasing trend in summer and winter and a decrease in autumn and spring (Figures $5 \mathrm{e}-5 \mathrm{~h}$ ), but only the decrease in autumn was statistically significant (Table 2). Although the Chla trends on the SB shelf were less clear, there appeared to be an overall decrease, with lower values during all seasons in recent years, while a very slight increase was seen in the open ocean domain (Figures 5a-5d). However, only the Chla decreases during winter and spring on the SB shelf and the decrease in spring (increase in winter) in the SB open ocean domain were significant (Tables 2 and S10). In contrast to the SB shelf region, upwelling on the $A B$ shelf showed small increases during all seasons (Figures 5e-5h), with only those in winter and spring being significant (Table 3). Chla in the AB shelf region appeared to increase during summer, showing overall higher values during the latter half of the time series, while the opposite pattern was observed in winter, autumn, and spring, with a general decreasing tendency since 2004 (Figures 6a-6d). However, linear regression showed that only the Chla increase in summer and the decrease in autumn were significant (Table 3), and similar to the NB shelf, substantial interannual and multiyear variability was observed in both the $\mathrm{SB}$ and $\mathrm{AB}$ shelf regions (Figures $5 \mathrm{a}-5 \mathrm{~d}$ and $6 \mathrm{a}-6 \mathrm{~d}$ ). In the $\mathrm{AB}$ open ocean domain, Chla values appeared to be increasing during winter and spring, while a general decreasing pattern occurred in summer and autumn. Although the Chla trends in the AB open ocean domain were statistically significant during all seasons, these values were very small (Table S11).

In general, elevated Chla concentrations were associated with higher microphytoplankton proportions, and the increases in microphytoplankton proportions were accompanied by concomitant decreases in nanophytoplankton and picophytoplankton in all shelf and open ocean regions. Microphytoplankton were dominant (>50\%) during all seasons in the NB shelf region throughout the 1997 to 2017 period, with nanophytoplankton being of secondary importance ( 30-35\%) and picophytoplankton contributing less than $12 \%$ to the total Chla (Figure 7). Accompanying the increasing trend in Chla (Figure 4), there appeared to be an overall significant, albeit small $\left(\leq 0.003 \pm 0.000\right.$ year $\left.^{-1}\right)$, increase in the microphytoplankton and a decrease in the nanophytoplankton and picophytoplankton proportions on the NB shelf during summer, autumn, and winter (Figure 5 and Table 1). However, during spring, only the nanophytoplankton showed a small but 

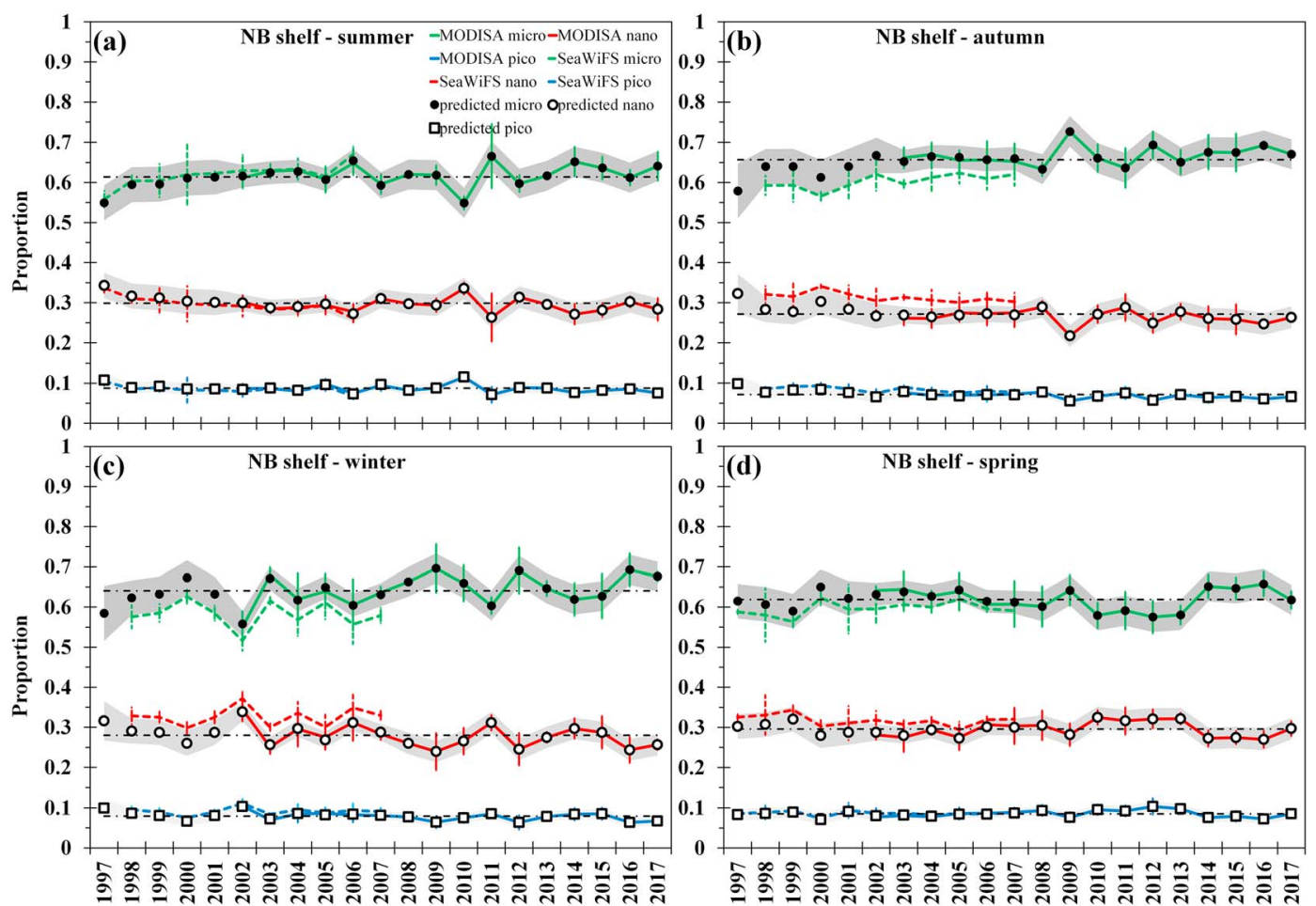

Figure 7. Seasonal mean fractional contribution of microphytoplankton, nanophytoplankton, and picophytoplankton to SeaWiFS and MODIS-Aqua chlorophyll $a\left(\mathrm{mg} / \mathrm{m}^{3}\right)$ in the Northern Benguela (NB) shelf region during austral (a) summer, (b) autumn, (c) winter, and (d) spring, for the period 1997 to 2017. Solid and dashed vertical lines indicate the standard deviation for MODIS-Aqua and SeaWiFS, respectively. Reconstructed (predicted) seasonal mean microphytoplankton, nanophytoplankton, and picophytoplankton are indicated as black dots, white dots, and white squares, respectively, and the $95 \%$ confidence interval for the predicted values are indicated as light gray shaded areas. Horizontal dashed-dotted black lines indicate the time series mean reconstructed (predicted) microphytoplankton, nanophytoplankton, and picophytoplankton in each season.

significant decrease (Table 1). In contrast to the NB shelf domain, the NB open ocean exhibited the opposite pattern with generally lower microphytoplankton and elevated nanophytoplankton and picophytoplankton proportions (Figures 8a and 8b). While there was frequent interchange between the dominance of nanophytoplankton and picophytoplankton during summer, the nanophytoplankton fraction remained dominant throughout the time series in autumn, with only a few years showing elevated microphytoplankton proportions (Figures $8 \mathrm{a}$ and $8 \mathrm{~b}$ ). During winter and spring, the picophytoplankton fraction was the smallest, and the nanophytoplankton fraction was the largest, except for a few years during winter when microphytoplankton proportions were higher (Figures $8 \mathrm{c}$ and 8d). Although significant, the trends for the various size classes in the NB open ocean were either very small $\left(\leq 0.002 \pm 0.000\right.$ year $\left.^{-1}\right)$, or indicated no change (Figure 8 and Table S9).

Similar to the NB shelf, microphytoplankton in the SB shelf also contributed the largest proportions to the total Chla, while the nanophytoplankton and picophytoplankton proportions averaged $\sim 30 \%$ and $10 \%$, respectively, during summer, autumn, and spring (Figures 9a, 9b, and 9d). Although the microphytoplankton (nanophytoplankton) proportions were overall lower (higher) during winter on the SB shelf, microphytoplankton remained dominant during all seasons, throughout the time series (Figure 9c). However, there were more years (2001-2003, 2005, 2007-2008, and 2012-2014) showing roughly equal microphytoplankton and nanophytoplankton proportions during winter. Picophytoplankton proportions were also generally higher in winter than during the other seasons. While there appeared to be a tendency toward lower microphytoplankton and higher nanophytoplankton and picophytoplankton fractions in the latter part of the time series, only the microphytoplankton and nanophytoplankton trends during spring and the picophytoplankton trend during autumn were significant in the SB shelf region (Figure 9), showing either very small values $\left(\leq 0.001 \pm 0.000\right.$ year $\left.^{-1}\right)$ or indicating no change (Table 2$)$. 

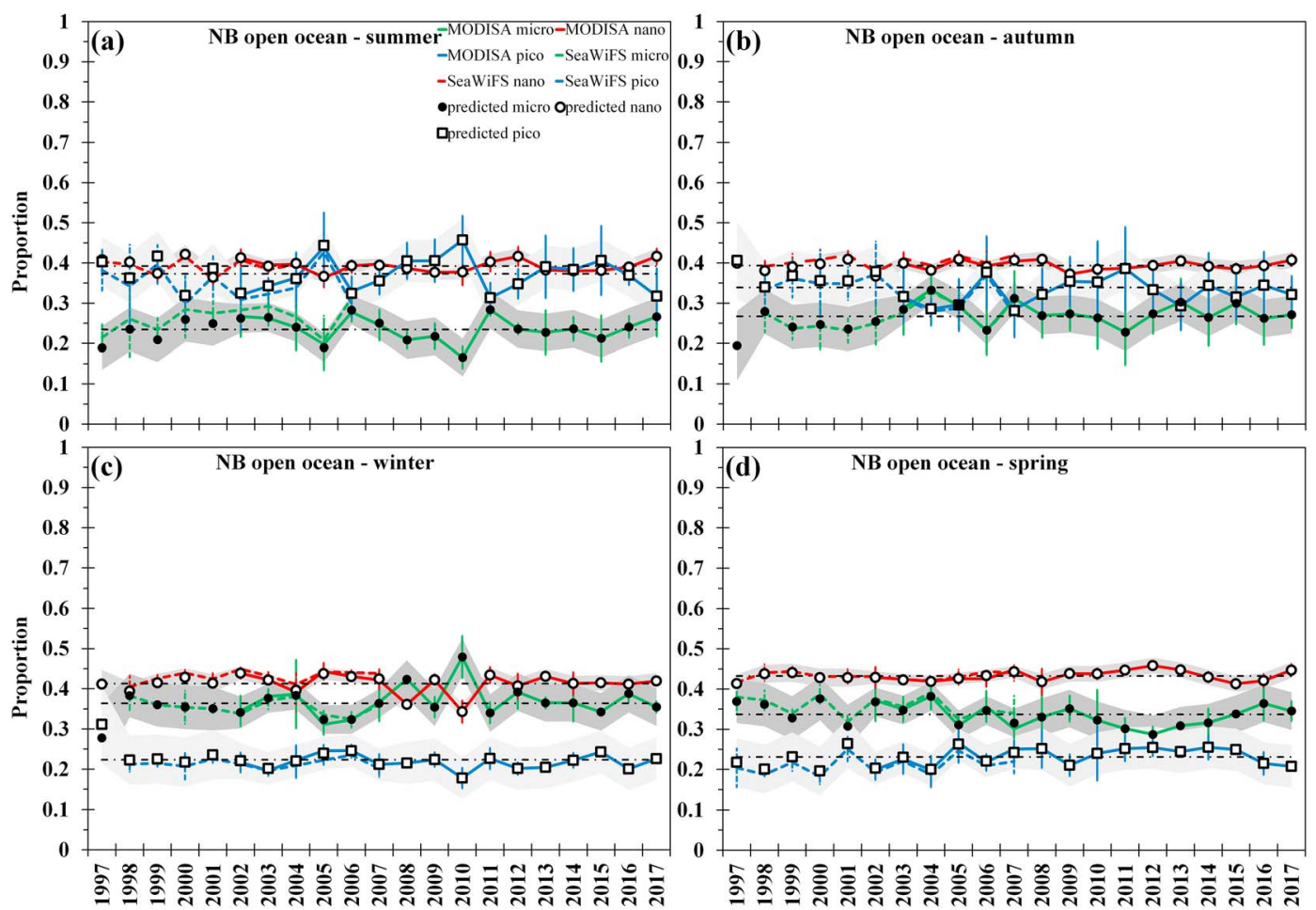

Figure 8. Seasonal mean fractional contribution of microphytoplankton, nanophytoplankton, and picophytoplankton to SeaWiFS and MODIS-Aqua chlorophyll $a\left(\mathrm{mg} / \mathrm{m}^{3}\right)$ in the Northern Benguela (NB) open ocean region during austral (a) summer, (b) autumn, (c) winter, and (d) spring, for the period 1997 to 2017. Solid and dashed vertical lines indicate the standard deviation for MODIS-Aqua and SeaWiFS, respectively. Reconstructed (predicted) seasonal mean microphytoplankton, nanophytoplankton, and picophytoplankton are indicated as black dots, white dots, and white squares, respectively, and the $95 \%$ confidence interval for the predicted values are indicated as light gray shaded areas. Horizontal dashed-dotted black lines indicate the time series mean reconstructed (predicted) microphytoplankton, nanophytoplankton, and picophytoplankton in each season.

In the $\mathrm{AB}$ shelf region, microphytoplankton were mostly dominant during autumn and spring, except for a few years (2000, 2004-2006, 2010-2012, and 2016), when microphytoplankton and nanophytoplankton proportions were either very similar or nanophytoplankton exceeded the microphytoplankton fraction. During summer and winter, there was more frequent switching between microphytoplankton and nanophytoplankton dominance throughout the time series, and picophytoplankton proportions were elevated during these seasons (Figure 11). A decreasing (increasing) pattern was evident for microphytoplankton (nanophytoplankton and picophytoplankton) fractions during autumn, winter, and spring, while no real change was evident in summer (Figure 11 and Table 3).

Picophytoplankton were the largest contributors to the total Chla throughout the time series, with slightly lower nanophytoplankton and minimal microphytoplankton proportions observed in the SB and AB open ocean regions in summer (Figures 10a and 12a). The opposite pattern was observed in these regions during winter and spring, when the nanophytoplankton fraction was the greatest and picophytoplankton proportions were slightly lower (Figures 10c and 10d and 12c and 12d). During autumn in the SB open ocean area, dominance regularly alternated between nanophytoplankton and picophytoplankton (Figure 10c), while there were only a few years when the picophytoplankton exceeded (or was roughly equal to) the nanophytoplankton fraction during autumn in the $\mathrm{AB}$ open ocean (Figure 12c). There appeared to be a small increase in microphytoplankton and nanophytoplankton proportions during summer, autumn, and winter in the SB open ocean, as well as winter and spring in the $\mathrm{AB}$ open ocean, but the pattern was reversed during spring in the SB open ocean and during summer and autumn in the AB open ocean (Figures 10 and 12). Linear regression showed that, despite being significant during autumn, winter, and spring in the SB open ocean and during all seasons in the $\mathrm{AB}$ open ocean, the trends were either very small $\left(\leq 0.001 \pm 0.000\right.$ year $\left.{ }^{-1}\right)$ or indicated no change (Tables S10 and S11). 

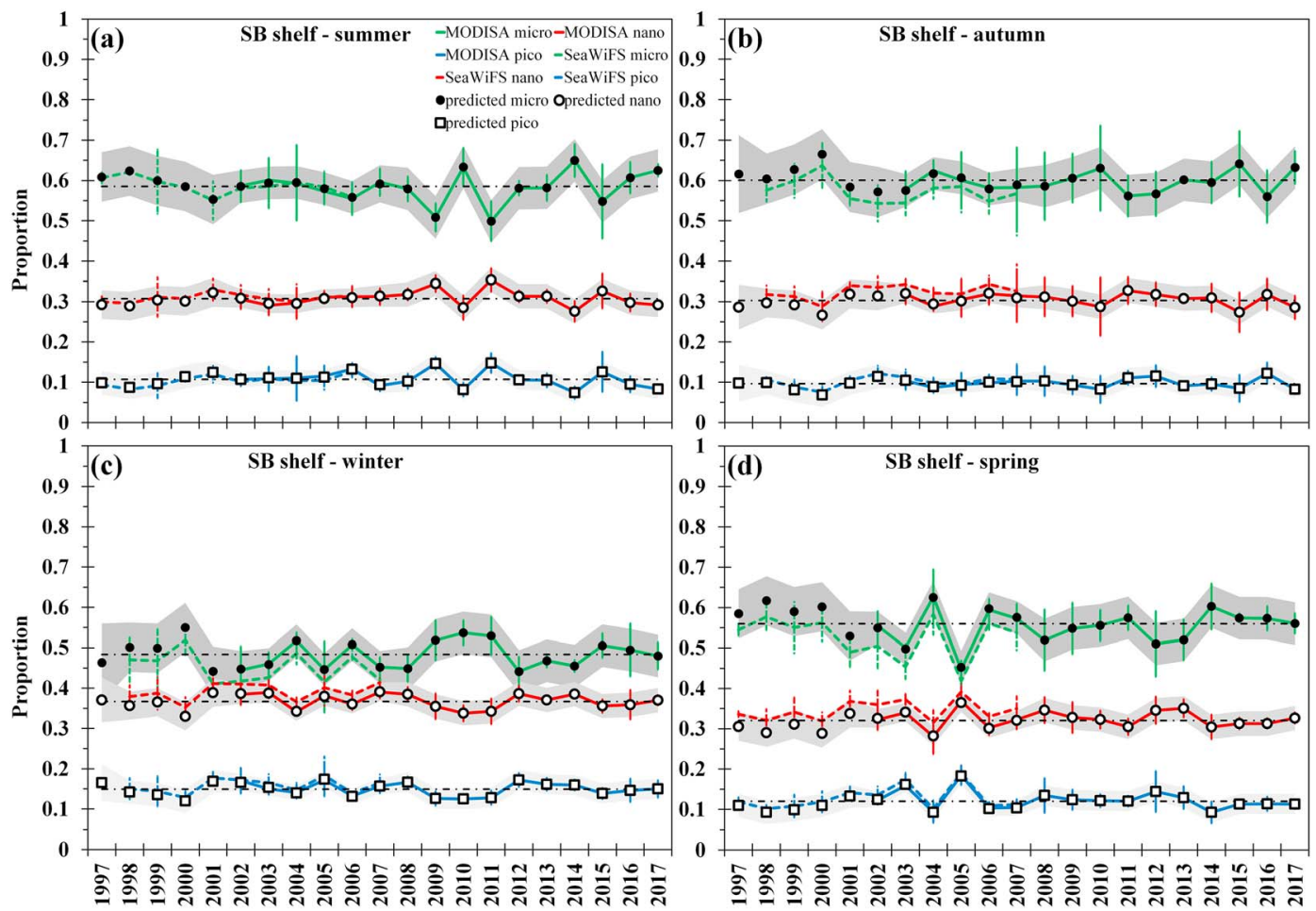

Figure 9. Seasonal mean fractional contribution of microphytoplankton, nanophytoplankton, and picophytoplankton to SeaWiFS and MODIS-Aqua chlorophyll $a\left(\mathrm{mg} / \mathrm{m}^{3}\right)$ in the Southern Benguela (SB) shelf region during austral (a) summer, (b) autumn, (c) winter, and (d) spring, for the period 1997 to 2017. Solid and dashed vertical lines indicate the standard deviation for MODIS-Aqua and SeaWiFS, respectively. Reconstructed (predicted) seasonal mean microphytoplankton, nanophytoplankton, and picophytoplankton are indicated as black dots, white dots, and white squares, respectively, and the $95 \%$ confidence interval for the predicted values are indicated as light gray shaded areas. Horizontal dashed-dotted black lines indicate the time series mean reconstructed (predicted) microphytoplankton, nanophytoplankton, and picophytoplankton in each season.

Seasonal differences in the relationship between upwelling and Chla, as well as the size classes, were observed in each of the shelf regions. In the NB shelf region, during summer, autumn, and winter, significant negative correlations were observed between upwelling and Chla and between upwelling and microphytoplankton proportions, with decreases in Chla and microphytoplankton related to increases in upwelling (Table 4). In contrast, during spring, these correlations were poor and not significant. Nanophytoplankton and picophytoplankton proportions showed the opposite pattern, with increases in the proportions associated with increases in upwelling. In the SB shelf region, Chla and microphytoplankton proportions exhibited a significant positive relationship during summer and autumn, where increases in upwelling were associated with increases in Chla. In contrast, a negative correlation was observed in the SB shelf region during winter, with an increase in upwelling corresponding to a decrease in Chla. Similar to the NB shelf region, the correlation between upwelling and Chla was poor and not significant during spring (Table 4). Correlations in the $\mathrm{AB}$ shelf region were overall weaker, and the only significant negative correlation between upwelling and Chla was observed in autumn (Table 4). While the picophytoplankton proportion showed a significant negative correlation with upwelling in summer on the AB shelf, during winter the microphytoplankton (nanophytoplankton and picophytoplankton) proportions showed significant negative (positive) correlations (Table 4).

\section{Discussion}

Comparisons between Chla values from the SeaWiFS and MODIS-Aqua platforms in the shelf and open ocean regions of the $\mathrm{NB}, \mathrm{SB}$, and $\mathrm{AB}$ revealed a good agreement, with data from both platforms displaying similar patterns of variability during the overlapping periods (Figures 2-6). These findings are in agreement with previous studies which have demonstrated a high level of consistency between the standard Chla 

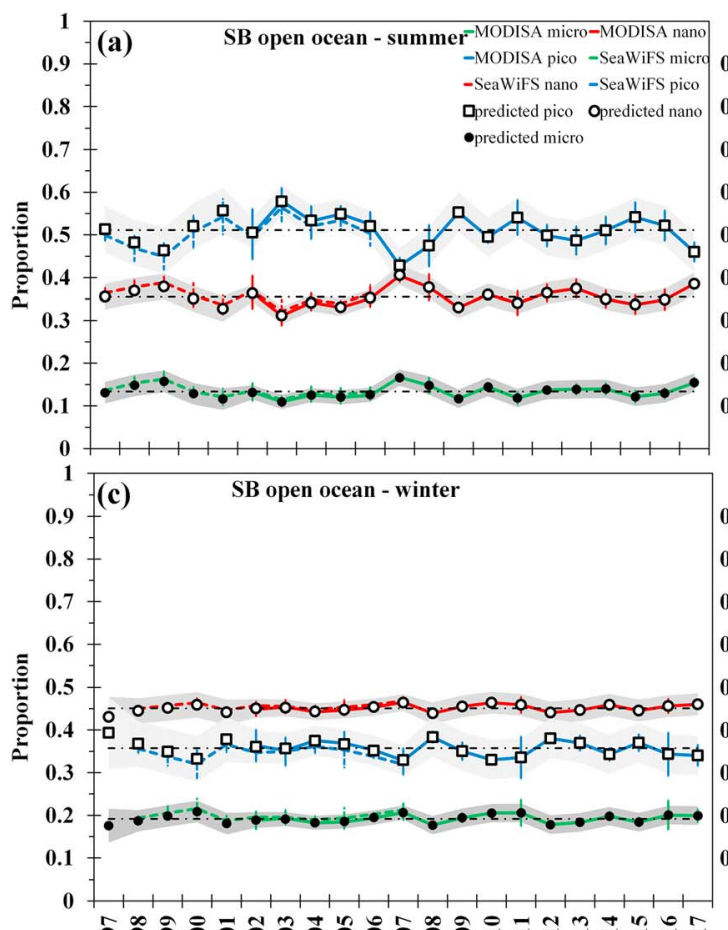

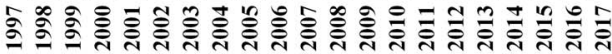
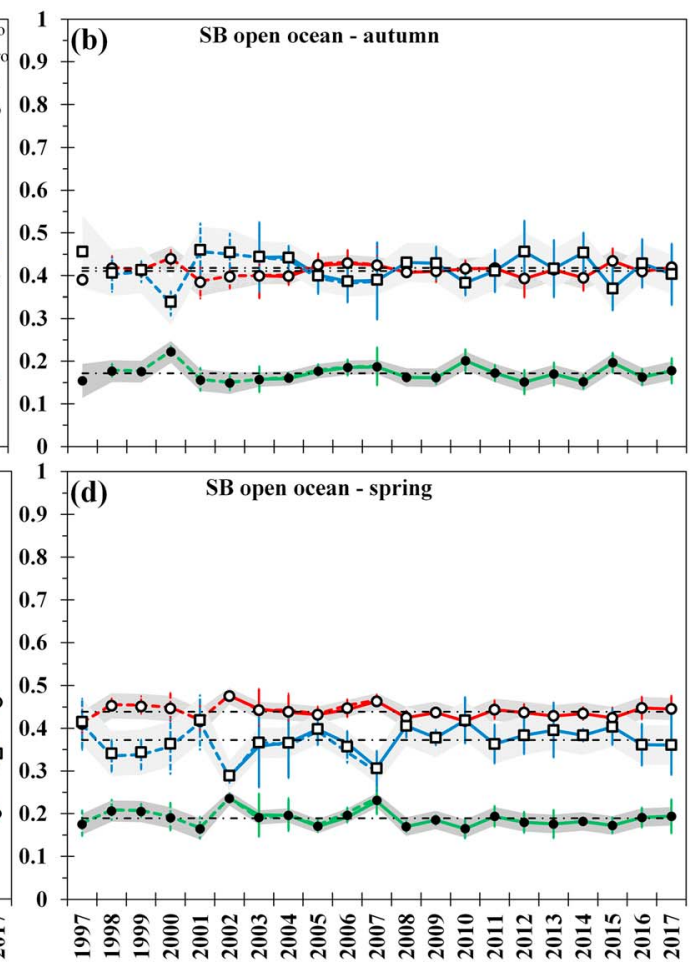

Figure 10. Seasonal mean fractional contribution of microphytoplankton, nanophytoplankton, and picophytoplankton to SeaWiFS and MODIS-Aqua chlorophyll $a\left(\mathrm{mg} / \mathrm{m}^{3}\right)$ in the Southern Benguela (SB) open ocean region during austral (a) summer, (b) autumn, (c) winter, and (d) spring, for the period 1997 to 2017. Solid and dashed vertical lines indicate the standard deviation for MODIS-Aqua and SeaWiFS, respectively. Reconstructed (predicted) seasonal mean microphytoplankton, nanophytoplankton, and picophytoplankton are indicated as black dots, white dots, and white squares, respectively, and the $95 \%$ confidence interval for the predicted values are indicated as light gray shaded areas. Horizontal dashed-dotted black lines indicate the time series mean reconstructed (predicted) microphytoplankton, nanophytoplankton, and picophytoplankton in each season.

products from the SeaWiFS and MODIS-Aqua platforms (Brewin et al., 2014; Mélin et al., 2017; Signorini et al., 2015). Despite the good agreement between the patterns of variability observed from the two platforms, MODIS-Aqua values were consistently higher than those from SeaWiFS in the shelf regions, and regional variations were evident with the largest differences occurring in the NB and the smallest in the $\mathrm{AB}$ shelf region, while minimal differences were noted in the open ocean domains (Figures 2-6). These results are similar to the findings of Marrari et al. (2017) for Large Marine Ecosystems around South and Western Central America, where MODIS-Aqua was also found to overestimate Chla compared to SeaWiFS.

While it is beyond the scope of the current study to identify and describe all potential sources of the discrepancies between the SeaWiFS and MODIS-Aqua data sets, some of those more pertinent to the BUS are briefly discussed. The tighter relationships in the open ocean domains as opposed to the shelf regions were expected, since the standard Chla algorithms applied to the SeaWiFS and MODIS-Aqua data sets were designed for open ocean (case 1) waters (Morel \& Prieur, 1977). While the majority of the shelf waters in the BUS can be classified as case 1, there are certain event-scale conditions where this classification may not hold and could account for some of the differences observed between the two platforms. In shallow $(<25 \mathrm{~m})$ waters in the California upwelling system, Kudela et al. (2006) demonstrated that during strong upwelling, while fluorescence was low, the optical signature of newly upwelled water was dominated by high backscatter from inorganic particles. This is also likely to be true for the BUS, where intense upwelling events are common and the associated rapid offshore advection of newly upwelled water under persistently strong upwelling-favorable winds, as observed in the NB shelf region (Figure 4; Lamont, García-Reyes, et al., 2018), could result in the Chla retrievals over large areas being impacted. The NB, SB, and AB shelf regions of the BUS are all subject to occasional very high biomass phytoplankton blooms (Louw et al., 2016; van der 

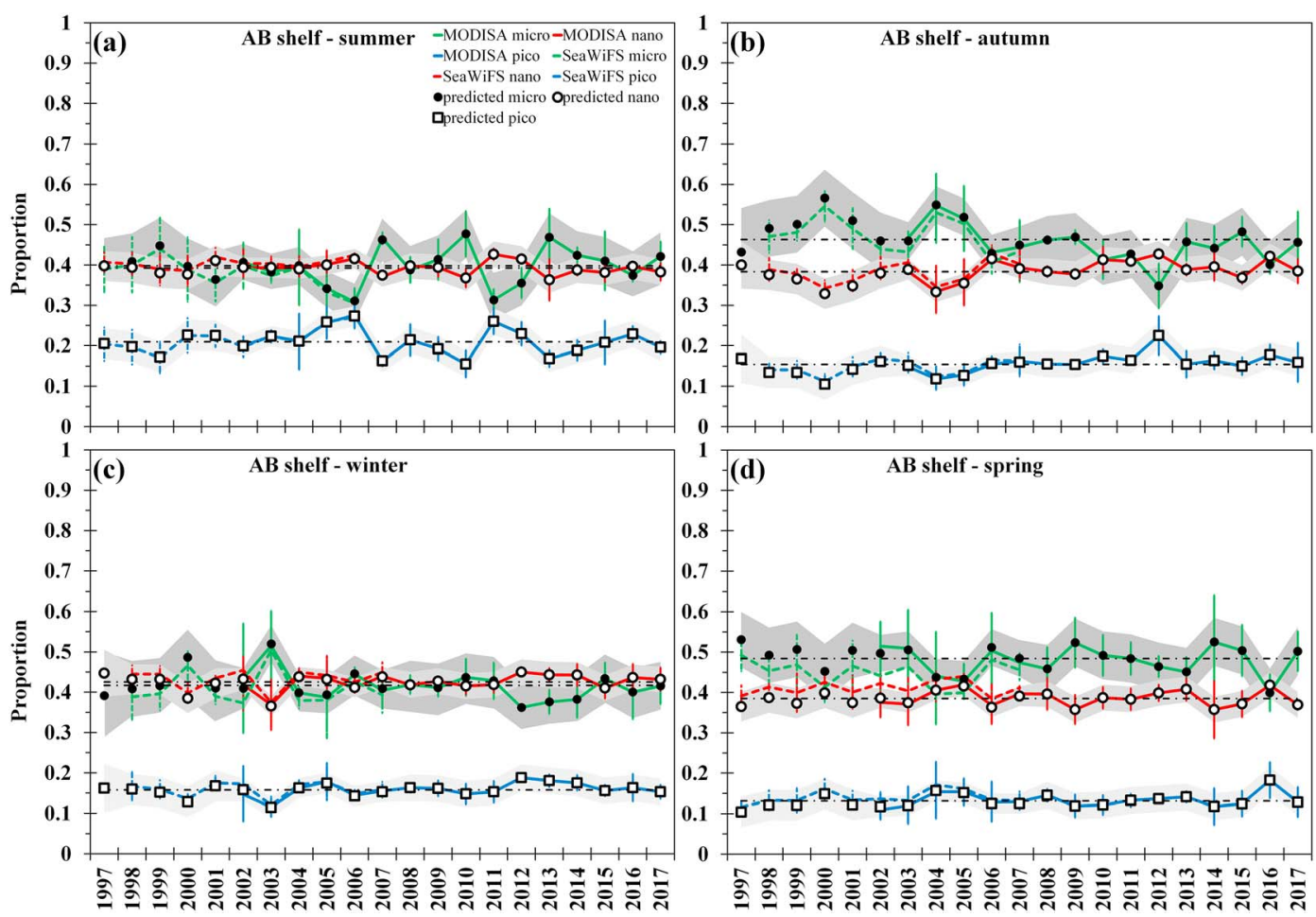

Figure 11. Seasonal mean fractional contribution of microphytoplankton, nanophytoplankton, and picophytoplankton to SeaWiFS and MODIS-Aqua chlorophyll $a\left(\mathrm{mg} / \mathrm{m}^{3}\right.$ ) in the Agulhas Bank (AB) shelf region during austral (a) summer, (b) autumn, (c) winter, and (d) spring, for the period 1997 to 2017. Solid and dashed vertical lines indicate the standard deviation for MODIS-Aqua and SeaWiFS, respectively. Reconstructed (predicted) seasonal mean microphytoplankton, nanophytoplankton, and picophytoplankton are indicated as black dots, white dots, and white squares, respectively, and the $95 \%$ confidence interval for the predicted values are indicated as light gray shaded areas. Horizontal dashed-dotted black lines indicate the time series mean reconstructed (predicted) microphytoplankton, nanophytoplankton, and picophytoplankton in each season.

Lingen et al., 2016; Verheye et al., 2016), and the intensity of absorption (or scattering in some cases) by these blooms can often be problematic for accurate atmospheric correction and result in poor Chla retrieval (Gordon \& Wang, 1994; M. Wang, 2006).

Additionally, extensive occurrence of fog/low clouds and large aerosol dust plumes from the Namib Desert, as well as sulfur eruptions, further hamper Chla retrieval, especially in the NB shelf region, and the effects of these vary seasonally. Although fog/low clouds can occur throughout the year, it is usually most extensive and frequent during spring and summer (Cermak, 2012), and the diurnal variations, with more occurrences during the mornings, are likely to impact SeaWiFS (local morning overpass) more than MODIS-Aqua (local afternoon overpass). Dust plumes commonly occur during strong easterly/northeasterly wind conditions during the austral winter months (Vickery et al., 2013), while sulfur eruptions are most prevalent during late summer and early autumn (Ohde \& Dadou, 2018). Furthermore, there are several other platform-specific contrasts which also contribute to the discrepancy between SeaWiFS and MODIS-Aqua retrievals, and these may or may not be apparent, depending on the choice of statistical comparison (Brewin et al., 2014; Djavidnia et al., 2010). Among these, the sensor tilt of $\sim 22^{\circ}$ performed by SeaWiFS to avoid sun glint during the summer months, versus the sun glint flagging applied to MODIS-Aqua data during processing, may result in substantial differences in Chla retrieved from the two platforms (Barnes \& Hu, 2016; Feng \& $\mathrm{Hu}, 2016)$.

It is likely that some combination of the above-mentioned factors is responsible for the weaker relationships observed between SeaWiFS and MODIS-Aqua in the NB shelf region, particularly during spring and summer (Figures 2-6). Nonetheless, the overall good agreement between the platforms, particularly in the SB and $\mathrm{AB}$ regions, is encouraging and supports the merging of the various data sets, similar to previous global studies (Brewin et al., 2014; Mélin et al., 2017). The use of a GLM to reconstruct the time series over the SeaWiFS period effectively removed the systematic biases between the SeaWiFS and MODIS-Aqua Chla 


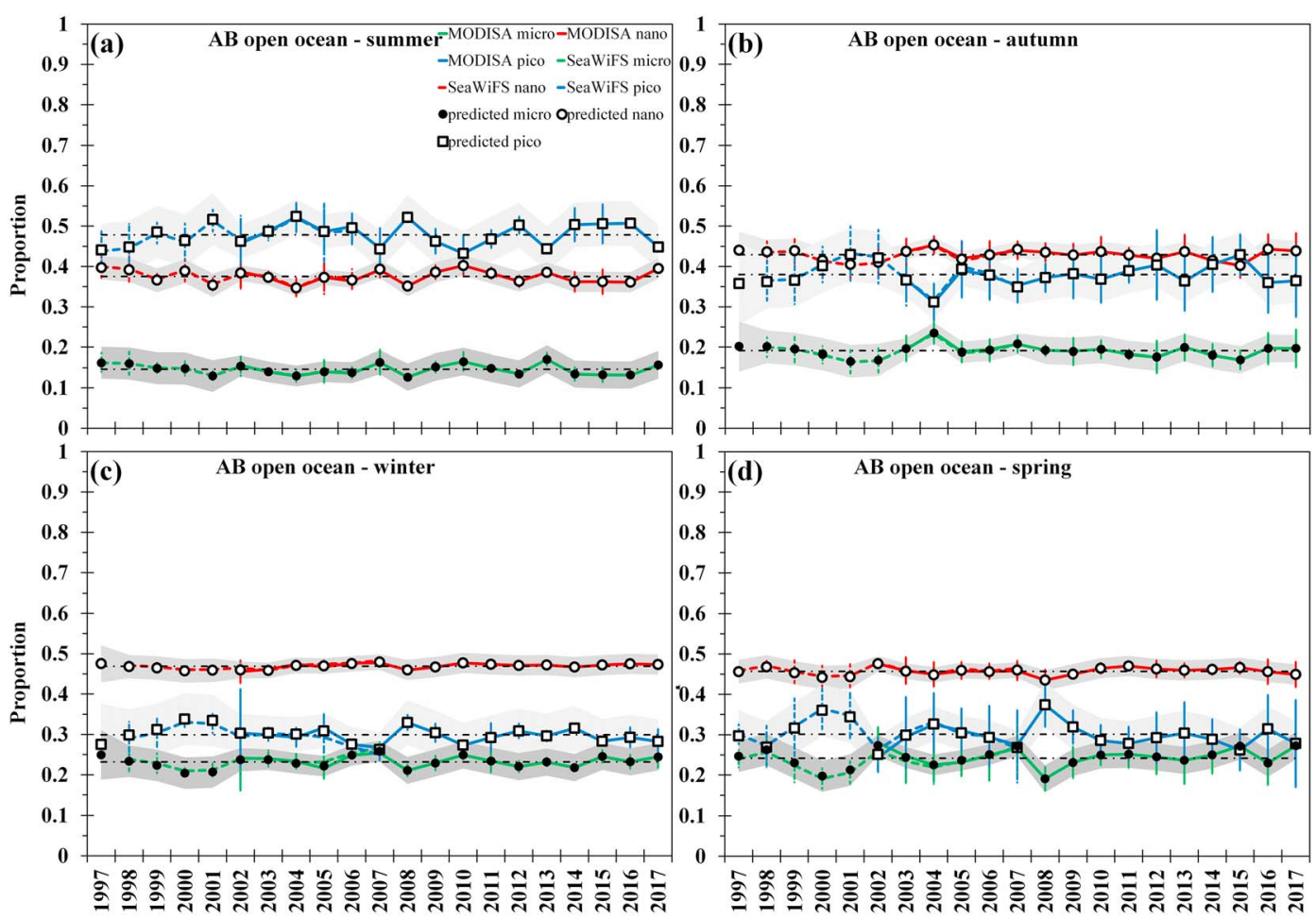

Figure 12. Seasonal mean fractional contribution of microphytoplankton, nanophytoplankton, and picophytoplankton to SeaWiFS and MODIS-Aqua chlorophyll $a\left(\mathrm{mg} / \mathrm{m}^{3}\right)$ in the Agulhas Bank (AB) open ocean region during austral (a) summer, (b) autumn, (c) winter, and (d) spring, for the period 1997 to 2017 . Solid and dashed vertical lines indicate the standard deviation for MODIS-Aqua and SeaWiFS, respectively. Reconstructed (predicted) seasonal mean microphytoplankton, nanophytoplankton, and picophytoplankton are indicated as black dots, white dots, and white squares, respectively, and the $95 \%$ confidence interval for the predicted values are indicated as light gray shaded areas. Horizontal dashed-dotted black lines indicate the time series mean reconstructed (predicted) microphytoplankton, nanophytoplankton, and picophytoplankton in each season.

and size classes while still retaining the temporal variability observed over the SeaWiFS period and provided a contiguous 20-year time series for the description of long-term trends in the BUS.

While surface Chla measurements are considered to be reasonably representative of phytoplankton biomass in the euphotic zone of the NB and SB shelf regions (Barlow et al., 2005, 2006; Brown et al., 1991; Lamont, Brewin, et al., 2018; Louw et al., 2016), subsurface Chla maxima commonly occur on the AB shelf (Brown \& Cochrane, 1991; Brown et al., 1991; Probyn, 1992; Probyn et al., 1994), as well as in the open ocean domains of each of these regions (Lamont, Brewin, et al., 2018). Thus, the variations of satellite Chla and size structure presented in this study are considered to represent the surface layer only. In the NB shelf region, in situ integrated Chla data off Walvis Bay $\left(23^{\circ} \mathrm{S}\right)$ showed a decline from 2001 to 2006, followed by an increase with the highest values observed during 2009-2011 (Jarre et al., 2015; Muller-Karger et al., 2017). A similar pattern was illustrated by Louw et al. (2016, see their Figure 5), but the paucity of in situ measurements, particularly after 2005, may be aliasing this observed pattern to some degree. Comparable long-term in situ Chla time series have not been sustained in the SB shelf region, but monthly values integrated across the shelf in the St. Helena Bay $\left(32^{\circ} \mathrm{S}\right)$ area between 2000 and 2008 show strong seasonal and interannual variations, with no clear long-term trend (Hutchings et al., 2009; Muller-Karger et al., 2017), and suggest that the increase in the in situ Chla during the 1980s and early-mid 1990s reported by Verheye (2000) has not continued to the 2000s (Jarre et al., 2015). In the AB shelf region, there are even fewer published long-term records of in situ Chla against which satellite time series can be compared (Muller-Karger et al., 2017), but an investigation of Chla values between 1971 and 1989 showed a marked seasonal cycle, with a slight overall decline in mean annual Chla (Brown \& Cochrane, 1991).

Although previous studies have described a good agreement between in situ and satellite Chla with regard to seasonal and shorter-term changes and spatial variations (e.g., Lamont, Barlow, et al., 2018; Lamont, Brewin, et al., 2018), it is difficult to relate the interannual and long-term in situ patterns described above 
Table 1

Linear Regression Analysis Results, Showing the Trend \pm Standard Error (Std. error) per Year for the 15-Year Low-Pass Filtered Upwelling $\left(\mathrm{m}^{3}\right.$. $\left.\mathrm{s}^{-1} \cdot 100 \mathrm{~m}^{-1}\right)$, Chlorophyll a (Chla, $\left.\mathrm{mg} / \mathrm{m}^{3}\right)$, and the Proportions of Microphytoplankton, Nanophytoplankton, and Picophytoplankton in the Northern Benguela (NB) Shelf Domain

\begin{tabular}{llrrrc}
\hline NB shelf & & Trend \pm Std. error & \multicolumn{1}{c}{$F_{1,20}$} & \multicolumn{1}{c}{$R^{2}$} & \multicolumn{1}{c}{$p$} \\
\hline \multirow{2}{*}{ Summer } & Upwelling & $-\mathbf{- 2 1 , 4 7 5} \pm \mathbf{2 , 6 7 4}$ & $\mathbf{6 4 . 5 2 3}$ & $\mathbf{0 . 7 7 3}$ & $<\mathbf{0 . 0 0 1}$ \\
& Chla & $0.040 \pm 0.004$ & 100.413 & 0.841 & $<0.001$ \\
& Micro & $0.002 \pm 0.000$ & 67.845 & 0.781 & $<0.001$ \\
& Nano & $\mathbf{- 0 . 0 0 2} \pm \mathbf{0 . 0 0 0}$ & $\mathbf{5 6 . 5 1 9}$ & $\mathbf{0 . 7 4 8}$ & $<\mathbf{0 . 0 0 1}$ \\
& Pico & $\mathbf{- 0 . 0 0 1} \pm \mathbf{0 . 0 0 0}$ & $\mathbf{7 6 . 5 5 0}$ & $\mathbf{0 . 8 0 1}$ & $<\mathbf{0 . 0 0 1}$ \\
Autumn & Upwelling & $\mathbf{- 5 6 , 3 5 3} \pm \mathbf{2 , 7 0 1}$ & $\mathbf{4 3 5 . 1 5 3}$ & $\mathbf{0 . 9 5 8}$ & $<\mathbf{0 . 0 0 1}$ \\
& Chla & $0.042 \pm 0.006$ & 50.829 & 0.728 & $<0.001$ \\
& Micro & $0.003 \pm 0.000$ & 126.823 & 0.870 & $<0.001$ \\
& Nano & $-\mathbf{0 . 0 0 2} \pm \mathbf{0 . 0 0 0}$ & $\mathbf{1 1 9 . 3 8 1}$ & $\mathbf{0 . 8 6 3}$ & $<\mathbf{0 . 0 0 1}$ \\
& Pico & $\mathbf{- 0 . 0 0 1} \pm \mathbf{0 . 0 0 0}$ & $\mathbf{1 3 8 . 9 0 9}$ & $\mathbf{0 . 8 8 0}$ & $<\mathbf{0 . 0 0 1}$ \\
Winter & Upwelling & $\mathbf{- 1 7 , 0 0 4} \pm \mathbf{1 , 5 1 3}$ & $\mathbf{1 2 6 . 3 5 4}$ & $\mathbf{0 . 8 6 9}$ & $<\mathbf{0 . 0 0 1}$ \\
& Chla & $0.039 \pm 0.001$ & 850.366 & 0.978 & $<0.001$ \\
& Micro & $0.003 \pm 0.000$ & $1,063.191$ & 0.982 & $<0.001$ \\
& Nano & $\mathbf{- 0 . 0 0 2} \pm \mathbf{0 . 0 0 0}$ & $\mathbf{1 , 0 7 4 . 0 5 6}$ & $\mathbf{0 . 9 8 3}$ & $<\mathbf{0 . 0 0 1}$ \\
& Pico & $\mathbf{- 0 . 0 0 1} \pm \mathbf{0 . 0 0 0}$ & $\mathbf{7 7 3 . 2 0 2}$ & $\mathbf{0 . 9 7 6}$ & $<\mathbf{0 . 0 0 1}$ \\
Spring & Upwelling & $\mathbf{- 8 , 2 0 4} \pm \mathbf{1 , 5 8 3}$ & $\mathbf{2 6 . 8 4 8}$ & $\mathbf{0 . 5 8 6}$ & $<\mathbf{0 . 0 0 1}$ \\
& Chla & $0.017 \pm 0.009$ & 3.824 & 0.168 & 0.065 \\
& Micro & $0.001 \pm 0.000$ & 4.281 & 0.184 & 0.052 \\
& Nano & $\mathbf{- 0 . 0 0 1} \pm \mathbf{0 . 0 0 0}$ & $\mathbf{7 . 6 7 5}$ & $\mathbf{0 . 2 8 8}$ & $\mathbf{0 . 0 1 2}$ \\
& Pico & $0.000 \pm 0.000$ & 0.206 & 0.011 & 0.655 \\
\hline
\end{tabular}

Note. $F_{1,20}$ indicates the $F$ statistic and degrees of freedom. Gray shading indicates significant results, and bold values indicate negative trends. to those observed from satellite data. This is primarily due to the spatial and temporal differences in the sampling resolution between the in situ and satellite data. Most of the in situ data sets described above are composed of samples collected once per month, and thus any interannual or long-term patterns described from them are likely to be aliased by high event-scale (6-10-day cycles) variability of phytoplankton responses, as well as the highly varied pulsed nature of upwelling, particularly in the southern BUS (Hutchings et al., 2012, 2009, 2006). In contrast, the monthly satellite averages include observations throughout each month, depending on availability of data free from cloud and other contamination. Furthermore, the in situ data sets are often very localized in space, being collected along single transects (Hutchings et al., 2009; Louw et al., 2016), or within very limited areas on the shelf (Brown \& Cochrane, 1991; Hutchings et al., 2012; Jarre et al., 2015; Verheye, 2000), while the large satellite data sets often need to be condensed in some way, usually by temporal and/or spatial averaging or by generating indices, to facilitate presentation of patterns and processes (Demarcq et al., 2003, 2007, 2012; Lamont, Brewin, et al., 2018, Weeks et al., 2006). Another reason contributing to the difficulty in comparing interannual and long-term in situ and satellite trends is that in situ data sets are often integrated vertically (Jarre et al., 2015; Louw et al., 2016), while satellite observations are considered representative of only surface phytoplankton populations and likely do not fully detect subsurface communities.

Numerous studies have documented long-term trends and interannual variations in satellite Chla at global scales, with findings varying from declining trends (Behrenfeld et al., 2006; Boyce et al., 2010, 2014; Doney, 2006) to increasing trends (Gregg et al., 2005). These changes have been related to climate-driven fluctuations in environmental conditions, with increases in Chla associated with warming at high latitudes and the reverse occurring at low latitudes (Behrenfeld et al., 2006; Martinez et al., 2009; Polovina et al., 2008). However, Vantrepotte and Mélin (2009) demonstrated that Chla at high (low) latitudes does not always increase (decrease) as expected in response to ocean warming (also see Raitsos et al., 2015), and it has been postulated that cancellation of positive and negative trends in different seasons was likely responsible for this, and several studies (Chavez et al., 2011; Hammond et al., 2017; Martinez et al., 2009) have shown that there were regional differences with both positive and negative trends observed across the global ocean.

While regression analyses were significant during most seasons, the trend values indicated little to no change in the long-term linear trends of Chla and proportions of microphytoplankton, nanophytoplankton, and picophytoplankton over the 1997-2018 period in the NB, SB, and AB regions (Figures 7-12 and Tables 1-3). This may be due to the reversal of trends from the SeaWiFS to MODIS-Aqua periods in each of the regions. This is evident during most seasons in the $\mathrm{NB}, \mathrm{SB}$, and $\mathrm{AB}$ shelf and open ocean regions for Chla (Figures 4-6), as well as the size fractions (Figures 7-12), where significant increases or decreases during the SeaWiFS period are replaced by the opposite or no trend during the MODIS-Aqua period. This reversal of trends has also been observed in the global ocean where primarily negative SeaWiFS trends (Behrenfeld et al., 2006; Chavez et al., 2011; Polovina et al., 2008; Vantrepotte \& Mélin, 2009) have been replaced by positive or no clear MODIS-Aqua trends (Mélin et al., 2017). The current study also revealed regional differences in the patterns and trends, often with opposing trends being observed during the various seasons in the BUS. In agreement with the findings of Vantrepotte and Mélin (2009), these opposing seasonal trends are neutralized when examining annual means (data not shown), yielding a lack of discernible long-term trends.

Mesoscale variability in the form of eddies and fronts are known to have a substantial influence on phytoplankton biomass and production through their ability to either uplift nutrient-rich waters to the euphotic zone, in the case of cyclonic eddies, or subduct warmer surface waters resulting in the deepening of the 
Table 2

Linear Regression Analysis Results, Showing the Trend \pm Standard Error (Std. error) per Year for the 15-Year Low-Pass Filtered Upwelling $\left(\mathrm{m}^{3}\right.$. $\left.\mathrm{s}^{-1} \cdot 100 \mathrm{~m}^{-1}\right)$, Chlorophyll a (Chla, $\left.\mathrm{mg} / \mathrm{m}^{3}\right)$, and the Proportions of Microphytoplankton, Nanophytoplankton, and Picophytoplankton in the Southern Benguela (SB) Shelf Domain

\begin{tabular}{|c|c|c|c|c|c|}
\hline SB shelf & & Trend \pm Std. error & $F_{1,20}$ & $R^{2}$ & $p$ \\
\hline \multirow[t]{5}{*}{ Summer } & Upwelling & $511 \pm 419$ & 1.484 & 0.072 & 0.238 \\
\hline & Chla & $-0.003 \pm 0.002$ & 1.843 & 0.088 & 0.191 \\
\hline & Micro & $0.000 \pm 0.001$ & 0.070 & 0.004 & 0.794 \\
\hline & Nano & $0.000 \pm 0.000$ & 1.592 & 0.077 & 0.222 \\
\hline & Pico & $0.000 \pm 0.000$ & 0.444 & 0.023 & 0.513 \\
\hline \multirow[t]{5}{*}{ Autumn } & Upwelling & $-3,942 \pm 999$ & 15.572 & 0.450 & 0.001 \\
\hline & Chla & $-0.002 \pm 0.004$ & 0.179 & 0.009 & 0.677 \\
\hline & Micro & $-0.001 \pm 0.000$ & 4.303 & 0.185 & 0.052 \\
\hline & Nano & $0.000 \pm 0.000$ & 2.082 & 0.099 & 0.165 \\
\hline & Pico & $0.000 \pm 0.000$ & 17.511 & 0.480 & 0.001 \\
\hline \multirow[t]{5}{*}{ Winter } & Upwelling & $18 \pm 18$ & 1.016 & 0.051 & 0.326 \\
\hline & Chla & $-0.007 \pm 0.002$ & 12.120 & 0.389 & 0.002 \\
\hline & Micro & $0.000 \pm 0.000$ & 0.426 & 0.022 & 0.522 \\
\hline & Nano & $0.000 \pm 0.000$ & 1.074 & 0.053 & 0.313 \\
\hline & Pico & $0.000 \pm 0.000$ & 0.097 & 0.005 & 0.759 \\
\hline \multirow[t]{5}{*}{ Spring } & Upwelling & $-90 \pm 136$ & 0.436 & 0.022 & 0.517 \\
\hline & Chla & $-0.023 \pm 0.004$ & 31.819 & 0.626 & $<0.001$ \\
\hline & Micro & $-0.001 \pm 0.001$ & 4.636 & 0.196 & 0.044 \\
\hline & Nano & $0.001 \pm 0.000$ & 13.626 & 0.418 & 0.002 \\
\hline & Pico & $0.000 \pm 0.000$ & 0.837 & 0.042 & 0.372 \\
\hline
\end{tabular}

Note. $F_{1,20}$ indicates the $F$ statistic and degrees of freedom. Gray shading indicates significant results, and bold values indicate negative trends. nutricline, as in the case of anticyclonic eddies (Falkowski et al., 1991; Gaube et al., 2015; Oschlies \& Garçon, 1998). Various responses in phytoplankton biomass and productivity have also been documented at eddy peripheries in relation to stronger vertical velocities, enhanced mixing, as well as advection and entrainment (Lévy et al., 2012; Mahadevan, 2016; Quartly \& Srokosz, 2004). However, in Eastern Boundary Upwelling Systems, mesoscale eddies are often observed to have a negative impact, with mixing and stirring (Rossi et al., 2008, 2009; Y. Wang et al., 2018), as well as offshore transport and subduction of biomass (Rubio et al., 2018; Y. Wang et al., 2018) and nutrients (Gruber et al., 2011), resulting in a reduction of phytoplankton biomass and production in shelf regions. Since we investigated seasonal means of Chla and phytoplankton size classes, we could not examine the direct impacts of mesoscale features in the current study. However, previous investigations in the Benguela system have documented substantial offshore transport associated with eddies (Chaigneau et al., 2009; Hall \& Lutjeharms, 2011; Rossi et al., 2008, 2009; Rubio et al., 2009), as well as their influence in reducing phytoplankton biomass and production (Gruber et al., 2011; Hernández-Carrasco et al., 2014; Lachkar \& Gruber, 2012). Similarly, studies on the impacts of filaments on the Benguela ecosystem have also been infrequent, but they have been observed to extend considerable distances offshore and have been associated with substantial offshore transport of shelf waters (Duncombe Rae, Boyd, et al., 1992, Duncombe Rae, Shillington, et al., 1992; Lutjeharms et al., 1991; Shannon \& Nelson, 1996; Shillington et al., 1992). Recent modeling studies in the California upwelling system have predicted that future increases in eddy activity, together with changes in upwelling-favorable alongshore winds, as well as wind stress curl, will result in increased nutrient fluxes in both the coastal and offshore regions and yield spatially variable increases/decreases in phytoplankton biomass and production, as well as changes in community structure (Xui et al., 2018).

A recent study of the impact of zooplankton abundance on export fluxes of two different phytoplankton populations revealed that copepod grazing decreased the export efficiency in diatom-dominated mesocosms by altering the phytoplankton community structure and/or preventing their aggregation (Moriceau et al., 2018). In contrast, copepods increased phytoplankton growth, aggregation, and fecal pellet production in flagellate-dominated mesocosms (Moriceau et al., 2018). While their study illustrated the importance of considering the influence of zooplankton when trying to understand variations in phytoplankton biomass and community structure, patterns of variability in phytoplankton and zooplankton populations determined from field observations are not always easy to reconcile. This is especially true for the BUS, where it has been proposed that the observed changes in zooplankton abundance and community structure result from the combined effects of bottom-up control (oceanographic and lower trophic biological processes) and top-down control, primarily through the effect of predation by anchovy and sardine (Huggett et al., 2009; Verheye, 2000; Verheye et al., 1998, 2016, 2017; Verheye \& Richardson, 1998).

Concomitant with overall decreases in zooplankton abundance, there has been a pronounced shift in dominance from larger to smaller species in the $\mathrm{NB}, \mathrm{SB}$, and $\mathrm{AB}$ shelf regions, suggesting a long-term change from a cooler to a warmer ecosystem (Huggett et al., 2016; Verheye, 2000; Verheye et al., 1998, 2016, 2017). Strong evidence of bottom-up control on zooplankton communities was presented by Verheye (2000), with concomitant long-term increases in nutrient enrichment, surface phytoplankton biomass, and zooplankton abundance during the 1980s and early-mid 1990s. There seems to be a general agreement between the long-term trends in phytoplankton biomass and size structure presented in the current study and published zooplankton trends for autumn in the SB and for spring in the AB shelf region (Huggett et al., 2016, 2009; Verheye et al., 1998, 2016, 2017), with overall decreasing patterns in Chla and microphytoplankton fractions corresponding to decreases in zooplankton abundance and community structure 
Table 3

Linear Regression Analysis Results, Showing the Trend \pm Standard Error (Std. error) per Year for the 15-Year Low-Pass Filtered Upwelling $\left(\mathrm{m}^{3}\right.$. $\left.\mathrm{s}^{-1} \cdot 100 \mathrm{~m}^{-1}\right)$, Chlorophyll a (Chla, $\left.\mathrm{mg} / \mathrm{m}^{3}\right)$, and the Proportions of Microphytoplankton, Nanophytoplankton, and Picophytoplankton in the Agulhas Bank (AB) Shelf Domain

\begin{tabular}{|c|c|c|c|c|c|}
\hline $\mathrm{AB}$ shelf & & Trend \pm Std. error & $F_{1,20}$ & $R^{2}$ & $p$ \\
\hline \multirow[t]{5}{*}{ Summer } & Upwelling & $65 \pm 36$ & 3.245 & 0.146 & 0.088 \\
\hline & Chla & $0.009 \pm 0.002$ & 30.222 & 0.614 & $<0.001$ \\
\hline & Micro & $0.000 \pm 0.000$ & 1.152 & 0.057 & 0.296 \\
\hline & Nano & $0.000 \pm 0.000$ & 8.155 & 0.300 & 0.010 \\
\hline & Pico & $0.000 \pm 0.000$ & 0.043 & 0.002 & 0.838 \\
\hline \multirow{5}{*}{ Autumn } & Upwelling & $7 \pm 12$ & 0.294 & 0.015 & 0.594 \\
\hline & Chla & $-0.018 \pm 0.005$ & 11.457 & 0.376 & 0.003 \\
\hline & Micro & $-0.003 \pm 0.000$ & 49.758 & 0.724 & $<0.001$ \\
\hline & Nano & $0.002 \pm 0.000$ & 39.595 & 0.676 & $<0.001$ \\
\hline & Pico & $0.002 \pm 0.000$ & 61.780 & 0.765 & $<0.001$ \\
\hline \multirow[t]{5}{*}{ Winter } & Upwelling & $13 \pm 4$ & 13.713 & 0.419 & 0.002 \\
\hline & Chla & $-0.003 \pm 0.003$ & 0.971 & 0.049 & 0.337 \\
\hline & Micro & $-0.001 \pm 0.000$ & 6.553 & 0.256 & 0.019 \\
\hline & Nano & $0.000 \pm 0.000$ & 1.881 & 0.090 & 0.186 \\
\hline & Pico & $0.001 \pm 0.000$ & 16.812 & 0.469 & 0.001 \\
\hline \multirow[t]{5}{*}{ Spring } & Upwelling & $41 \pm 9$ & 23.479 & 0.553 & $<0.001$ \\
\hline & Chla & $-0.002 \pm 0.001$ & 1.345 & 0.066 & 0.261 \\
\hline & Micro & $-0.001 \pm 0.000$ & 46.044 & 0.708 & $<0.001$ \\
\hline & Nano & $0.000 \pm 0.000$ & 5.997 & 0.240 & 0.024 \\
\hline & Pico & $0.001 \pm 0.000$ & 96.371 & 0.835 & $<0.001$ \\
\hline
\end{tabular}

Note. $F_{1,20}$ indicates the $F$ statistic and degrees of freedom. Gray shading indicates significant results, and bold values indicate negative trends.
(Figures 5, 6, 9, and 11 and Tables 2 and 3). In contrast, the decreases in zooplankton abundance and community structure in summer on the $\mathrm{AB}$ shelf (Huggett et al., 2016, 2009; Verheye et al., 1998, 2016, 2017) appear to be associated with a small but significant increase in Chla (Table 3 ). The same applies to the NB shelf region, where observed long-term changes in phytoplankton show general increases in Chla and microphytoplankton proportions (Figures 4 and 7 and Table 1), while annual mean zooplankton patterns indicate an opposing trend with decreases in overall abundances and larger species dominance (Verheye et al., 2016, 2017).

Increasing Chla and microphytoplankton proportions in the NB shelf region (Figures 4 and 7) appears to be related to the overall decrease in upwelling-favorable wind conditions in recent years (Figure 4 and Table 3; Lamont, García-Reyes, et al., 2018), and indeed, these parameters seem to be strongly correlated (Table 4). Despite the substantial recent decrease, upwelling in the NB region is still an order of magnitude larger than that in the SB region (Figures 4 and 5; Lamont, García-Reyes, et al., 2018), and thus, it is possible that nutrient input to the euphotic zone is still sufficient to sustain elevated levels of phytoplankton, together with the associated reduction in turbulence and mixing (Jarre et al., 2015; Lamont, García-Reyes, et al., 2018; Tim et al., 2015) and the diminished grazing pressure from the lower zooplankton abundances (Verheye et al., 2016, 2017) possibly contributing to the observed increases in Chla and microphytoplankton fractions. On the AB shelf, the increase in Chla and microphytoplankton proportions during summer is in agreement with the observed increase in summer upwelling-favorable winds (Figure 6 and Tables 3 and 4; Lamont, García-Reyes, et al., 2018), which are likely yielding elevated nutrient concentrations more suitable to phytoplankton growth in the euphotic zone and favoring larger-celled phytoplankton, with lower zooplankton abundance exerting less grazing pressure on phytoplankton communities (Huggett et al., 2016; Verheye et al., 2017). In contrast, the correspondence between the long-term observations of upwelling (Lamont, García-Reyes, et al., 2018) and phytoplankton biomass and size structure variations in the SB region (Figures 5, 9, and 10 and Tables 2 and 4) is more variable, with positive correlations with Chla in summer and autumn and a negative correlation in winter. Despite the strong correlations between upwelling and Chla, as well as the size classes in the NB, $\mathrm{SB}$, and $\mathrm{AB}$ shelf regions, it is important to note that while the long-term decreases (increases) in upwelling, particularly in the NB shelf region, have been remarkably large and significant, the long-term increases (decreases) in Chla and size structure have been very small in comparison, suggesting the influence of additional mechanisms, such as zooplankton grazing and light availability, controlling the Chla and size structure in these regions. Furthermore, this study has highlighted seasonal differences in the relationship between upwelling and Chla in each of the shelf regions, with the strongest correlations observed in summer, autumn, and winter in the NB and SB shelf regions and only during autumn on the AB shelf.

In addition to changes in upwelling frequency and intensity (Jarre et al., 2015; Lamont, García-Reyes, et al., 2018; Tim et al., 2015), shifts in the properties of upwelling source waters have also been noted in the South Atlantic (de Souza et al., 2018; Karstensen \& Quadfasel, 2002; Salt et al., 2015; Venegas et al., 1998). While the impacts of such changes have not been described for the BUS, increased biomass and production in the California upwelling system have been related to elevated nitrate levels in source waters (Bograd et al., 2015; Rykaczewski and Dunne, 2010). Recent model experiments have demonstrated the strong influence of the Agulhas Current on the BUS through the intensification of shelf-edge currents which result in the uplift of cooler, less saline waters into the surface layers (Veitch \& Penven, 2017). Projected increases in the input of Agulhas Current waters into the South Atlantic (Beal et al., 2011; Biastoch et al., 2009) are likely to alter the properties of Central waters in the South Atlantic, not only by increases in temperature and salinity but also by resulting in decreases in nutrient and dissolved oxygen content, and thus have the potential to decrease the productivity of the Benguela ecosystem. 
Table 4

Correlation Coefficients and Significance (p) Values Between the 15-Year Low-Pass Filtered Upwelling $\left(\mathrm{m}^{3} \cdot \mathrm{s}^{-1} \cdot 100 \mathrm{~m}^{-1}\right)$ and the 15-Year Low-Pass Filtered Chlorophyll a (Chla, $\left.\mathrm{mg} / \mathrm{m}^{3}\right)$ and Proportions of Microphytoplankton, Nanophytoplankton, and Picophytoplankton in the $N B, S B$, and $A B$ Shelf Domains

\begin{tabular}{lrrrr}
\hline $\begin{array}{l}\text { NB shelf } \\
\text { upwelling }\end{array}$ & \multicolumn{1}{c}{ Chla } & \multicolumn{1}{c}{ Micro } & Nano & \multicolumn{1}{c}{ Pico } \\
\hline Summer & $\boldsymbol{r}=\mathbf{- 0 . 8 7 7}$ & $\boldsymbol{r}=\mathbf{- 0 . 7 8 1}$ & $r=0.796$ & $r=0.715$ \\
& $\boldsymbol{p}<\mathbf{0 . 0 0 1}$ & $\boldsymbol{p}<\mathbf{0 . 0 0 1}$ & $p<0.001$ & $p<0.001$ \\
Autumn & $\boldsymbol{r}=-\mathbf{0 . 8 8 0}$ & $\boldsymbol{r}=-\mathbf{0 . 9 6 1}$ & $r=0.955$ & $r=0.970$ \\
& $\boldsymbol{p}<\mathbf{0 . 0 0 1}$ & $\boldsymbol{p}<\mathbf{0 . 0 0 1}$ & $p<0.001$ & $p<0.001$ \\
Winter & $\boldsymbol{r}=\mathbf{- 0 . 9 2 1}$ & $\boldsymbol{r}=\mathbf{- 0 . 9 1 6}$ & $r=0.909$ & $r=0.928$ \\
& $\boldsymbol{p}<\mathbf{0 . 0 0 1}$ & $\boldsymbol{p}<\mathbf{0 . 0 0 1}$ & $p<0.001$ & $p<0.001$ \\
Spring & $r=0.184$ & $r=0.159$ & $\boldsymbol{r}=\mathbf{- 0 . 0 1 2}$ & $\boldsymbol{r}=\mathbf{- 0 . 4 9 3}$ \\
& $p=0.424$ & $p=0.493$ & $\boldsymbol{p}=\mathbf{0 . 9 6 0}$ & $\boldsymbol{p}=\mathbf{0 . 0 2 3}$
\end{tabular}

\begin{tabular}{lcrrr}
$\begin{array}{l}\text { SB shelf } \\
\text { upwelling }\end{array}$ & Chla & \multicolumn{1}{c}{ Micro } & Nano & \multicolumn{1}{c}{ Pico } \\
\hline Summer & $r=0.556$ & $r=0.735$ & $\boldsymbol{r}=\mathbf{- 0 . 5 6 6}$ & $\boldsymbol{r}=\mathbf{- 0 . 8 5 0}$ \\
& $p=0.009$ & $p<0.001$ & $\boldsymbol{p}=\mathbf{0 . 0 0 7}$ & $\boldsymbol{p}<\mathbf{0 . 0 0 1}$ \\
Autumn & $r=0.797$ & $r=0.956$ & $\boldsymbol{r}=\mathbf{- 0 . 9 1 4}$ & $\boldsymbol{r}=-\mathbf{0 . 9 7 9}$ \\
& $p<0.001$ & $p<0.001$ & $\boldsymbol{p}<\mathbf{0 . 0 0 1}$ & $\boldsymbol{p}<\mathbf{0 . 0 0 1}$ \\
Winter & $\boldsymbol{r}=\mathbf{- 0 . 7 9 8}$ & $\boldsymbol{r}=-\mathbf{0 . 6 4 7}$ & $r=0.597$ & $r=0.613$ \\
& $\boldsymbol{p}<\mathbf{0 . 0 0 1}$ & $\boldsymbol{p}=\mathbf{0 . 0 0 2}$ & $p=0.004$ & $p=0.003$ \\
Spring & $r=0.302$ & $r=0.438$ & $\boldsymbol{r}=\mathbf{- 0 . 3 6 4}$ & $\boldsymbol{r}=\mathbf{- 0 . 4 8 5}$ \\
& $p=0.184$ & $p=0.047$ & $\boldsymbol{p}=\mathbf{0 . 1 0 5}$ & $\boldsymbol{p}=\mathbf{0 . 0 2 6}$
\end{tabular}

$\mathrm{AB}$ shelf upwelling Chla Micro Nano Pico

\begin{tabular}{lrrrr}
\hline Summer & $r=0.420$ & $r=0.414$ & $\boldsymbol{r}=\mathbf{- 0 . 0 5 2}$ & $\boldsymbol{r}=\mathbf{- 0 . 5 4 0}$ \\
& $p=0.058$ & $p=0.062$ & $\boldsymbol{p}=\mathbf{0 . 8 2 2}$ & $\boldsymbol{p}=\mathbf{0 . 0 1 1}$ \\
Autumn & $\boldsymbol{r}=\mathbf{- 0 . 7 5 4}$ & $\boldsymbol{r}=\mathbf{- 0 . 3 8 2}$ & $r=0.427$ & $r=0.331$ \\
& $\boldsymbol{p}<\mathbf{0 . 0 0 1}$ & $\boldsymbol{p}=\mathbf{0 . 0 8 7}$ & $p=0.053$ & $p=0.142$ \\
Winter & $\boldsymbol{r}=\mathbf{- 0 . 4 0 8}$ & $\boldsymbol{r}=-\mathbf{0 . 6 9 1}$ & $r=0.463$ & $r=0.870$ \\
& $\boldsymbol{p}=\mathbf{0 . 0 6 6}$ & $\boldsymbol{p}=\mathbf{0 . 0 0 1}$ & $p=0.035$ & $p<0.001$ \\
Spring & $r=0.385$ & $\boldsymbol{r}=\mathbf{0 . 3 3 5}$ & $r=0.082$ & $r=0.416$ \\
& $p=0.084$ & $\boldsymbol{p}=\mathbf{0 . 1 3 8}$ & $p=0.723$ & $p=0.061$ \\
\hline
\end{tabular}

Note. Gray shading indicates significant results, and bold values indicate negative correlations. $\mathrm{NB}=$ Northern Benguela; $\mathrm{SB}=$ Southern Benguela; $\mathrm{AB}=$ Agulhas Bank.
Although numerous investigations have shown the utility of ocean color measurements and demonstrated good agreement with in situ observations, with regard to spatial and seasonal changes, as well as shorter-term variations (Lamont, Barlow, et al., 2018; Lamont, Brewin, et al., 2018), several inconsistencies with longer-term variations and trends have been highlighted, with in situ and satellite time series in some cases showing seemingly contradictory patterns (Jarre et al., 2015). As discussed by Verheye et al. (2016), in light of the limited availability of in situ data, validation of the long-term temporal changes identified from ocean color time series is challenging, particularly in regions such as the BUS and surrounding open ocean. The fact that satellite-derived Chla and size structure are considered to represent the surface layers only (Lamont, Barlow, et al., 2018; Lamont, Brewin, et al., 2018) highlights a critical gap in the sampling of phytoplankton communities from space and emphasizes the necessity of sustained accurate long-term subsurface measurements, for instance, through autonomous platforms such as biogeochemical Argo floats (Claustre et al., 2010). Nevertheless, these ocean color observations, together with the application of models to assess variations in size structure, as presented in this study, among others (Brewin et al., 2010, 2014; Hirata et al., 2009; Lamont, Barlow, et al., 2018; Lamont, Brewin, et al., 2018) provide new data sets which afford the opportunity for more detailed investigations of phytoplankton communities, as well as their responses to climate change and variation. Since phytoplankton communities form the base of marine ecosystems (Chassot et al., 2010; Field et al., 1998; Sathyendranath et al., 2017), such as the highly productive BUS which supports large fisheries and other ecosystem goods and services of substantial economic value (Kirkman et al., 2016; Verheye et al., 2016), understanding and monitoring variations in phytoplankton biomass and community structure is crucial to evaluating the functioning and health status of these ecosystems. To adequately monitor and understand ecosystem variability and change, long-term data sets are essential. Although the approach of using a GLM to reconstruct the time series over the SeaWiFS period in the current study is simpler than most existing methods (Grant et al., 2017; Maritorena \& Siegel, 2005; Mélin \& Sclep, 2015; Signorini et al., 2015) of combining SeaWiFS and MODIS-Aqua data, it yielded a contiguous 20-year data set by removing the systematic differences between SeaWiFS and MODIS-Aqua Chla and size fractions, without impacting the observed temporal variability over the SeaWiFS period.

In this study, a significant increase in Chla and microphytoplankton fractions was observed during all seasons in the NB shelf region and during summer in the $A B$ shelf region, while the opposite was noted during winter and spring on the SB shelf and in autumn on the $\mathrm{AB}$ shelf. As suggested by the $R^{2}$ values, most of these long-term linear trends explain a reasonably large proportion of the variance in each time series in the NB and AB regions but are generally much weaker in the SB region. The largest and most notable signal in each of the regions was the substantial interannual changes in both Chla and the size fractions. These findings are in agreement with various modeling studies which have demonstrated that long-term changes in physical properties were small in comparison to their interannual and decadal-scale variability and speculated that these gradual shifts would yield similarly slow changes in phytoplankton populations (Bopp et al., 2001; Boyd et al., 2008). Similarly, Henson et al. (2010) and Beaulieu et al. (2013) demonstrated that the magnitude of interannual to decadal-scale changes in satellite Chla time series is similar (or greater in some cases) to the magnitude of the long-term trends and concluded that these changes are not yet discernible from each other due to the relatively short length of the available contiguous observations. It was further demonstrated that in the 
Equatorial and South Atlantic Ocean, an average of 32-36 years of observations is required to be able to distinguish long-term climate-driven trends from interannual to decadal variations in Chla (Henson et al., 2010). In upwelling systems, such as the Benguela, where interannual to decadal changes are often much larger than those in more oligotrophic regions, as illustrated above, substantially more years of observations may be required before these various effects can be adequately distinguished. The current study presents the first 20-year analysis of long-term variations in surface phytoplankton biomass and community structure in the BUS and provides a necessary baseline against which future changes can be monitored and assessed.

\section{Acknowledgments}

Monthly averaged SeaWiFS (doi: 10.5067/ORBVIEW-2/SEAWIFS/L3M/ CHL/2018) and MODIS-Aqua (doi: 10.5067/AQUA/MODIS/L3M/CHL/ 2018) chlorophyll $a$ concentrations were provided by the Ocean Biology Processing Group (OBGP) and NASA's Goddard Space Flight Center (GSFC). NCEP-DOE Reanalysis 2 data were provided by the NOAA/OAR/ESRL PSD, Boulder, Colorado, United States (http://www.esrl.noaa.gov/psd/). Data products generated during this study are provided by the South African Department of Environmental Affairs (DEA; doi: 10.15493/DEA

MIMS.1000001-13). R.J.W.B. was supported by the NERC National Centre for Earth Observation, and T.L. and R. G.B. by the DEA and the South African National Research Foundation (NRF). Mr. Kobus Britz (DEA) is thanked for his assistance in acquiring the satellite data.

\section{References}

Bailey, S. W., \& Werdell, P. J. (2006). A multi-sensor approach for the on-orbit validation of ocean color satellite data products. Remote Sensing of Environment, 102(1-2), 12-23. https://doi.org/10.1016/j.rse.2006.01.015

Barlow, R. G., Louw, D., Balarin, M., \& Alheit, J. (2006). Pigment signatures of phytoplankton composition in the Northern Benguela ecosystem during spring. African Journal of Marine Science, 28(3-4), 479-491. https://doi.org/10.2989/18142320609504200

Barlow, R. G., Sessions, H., Balarin, M., Weeks, S., Whittle, C., \& Hutchings, L. (2005). Seasonal variation in phytoplankton in the Southern Benguela: Pigment indices and ocean colour. African Journal of Marine Science, 27(1), 275-287. https://doi.org/10.2989/ 18142320509504086

Barnes, B. B., \& Hu, C. (2016). Dependance of satellite ocean color data products on viewing angles: A comparison between SeaWiFS, MODIS, and VIIRS. Remote Sensing of Environment, 175, 120-129. https://doi.org/10.1016/j.rse.2015.12.048

Beal, L. M., de Ruijter, W. P. M., Biastoch, A., Zahn, R., \& SCOR/WCRP/IAPSO Working Group 136 (2011). On the role of the Agulhas system in ocean circulation and climate. Nature, 472, 429-436. https://doi.org/10.1038/nature09983

Beaulieu, C., Henson, S. A., Sarmiento, J. L., Dunne, J. P., Doney, S. C., Rykaczewski, R. R., \& Bopp, L. (2013). Factors challenging our ability to detect long-term trends in ocean chlorophyll. Biogeosciences, 10(4), 2711-2724. https://doi.org/10.5194/bg-10-2711-2013

Becker, J. J., Sandwell, D. T., Smith, W. H. F., Braud, J., Binder, B., Depner, J., et al. (2009). Global bathymetry and elevation data at 30 arc seconds resolution: SRTM30_PLUS. Marine Geodesy, 32(4), 355-371. https://doi.org/10.1080/01490410903297766

Behrenfeld, M. J., O'Malley, R. T., Siegal, D. A., McClain, C. R., Sarmiento, J. L., Feldman, G. C., et al. (2006). Climate-driven trends in contemporary ocean productivity. Nature, 444(7120), 752-755. https://doi.org/10.1038/nature05317

Belkin, I. M. (2009). Rapid warming of large marine ecosystems. Progress in Oceanography, 81(1-4), 207-213. https://doi.org/10.1016/j. pocean.2009.04.011

Biastoch, A., Böning, C. W., Schwarzkopf, F. U., \& Lutjeharms, J. R. E. (2009). Increase in Agulhas leakage due to poleward shift of Southern Hemisphere westerlies. Nature, 462(7272), 495-498. https://doi.org/10.1038/nature08519

Bograd, S. J., Buil, M. P., Di Lorenzo, E., Castro, C. G., Schroeder, I. D., Goericke, R., et al. (2015). Changes in source waters to the Southern California Bight. Deep-Sea Research Part II, 112, 42-52. https://doi.org/10.1016/j.dsr2.2014.04.009

Bopp, L., Monfray, P., Aumont, O., Dufresne, J.-L., Le Treut, H., Madec, G., et al. (2001). Potential impacts of climate change on marine export production. Global Biogeochemical Cycles, 15(1), 81-99. https://doi.org/10.1029/1999GB001256

Boyce, D. G., Dowd, M., Lewis, M. R., \& Worm, B. (2014). Estimating global chlorophyll changes over the past century. Progress in Oceanography, 122, 163-173. https://doi.org/10.1016/j.pocean.2014.01.004

Boyce, D. G., Lewis, M. R., \& Worm, B. (2010). Global phytoplankton decline over the past century. Nature, 466(7306), 591-596. https://doi. org/10.1038/nature09268

Boyd, P. W., Doney, S. C., Strzepek, R., Dusenberry, J., Lindsay, K., \& Fung, I. (2008). Climate-mediated changes to mixed-layer properties in the Southern Ocean: Assessing the phytoplankton response. Biogeosciences, 5(3), 847-864. https://doi.org/10.5194/bg-5-847-2008

Brewin, R. J. W., Hirata, T., Hardman-Mountford, N. J., Lavender, S. J., Sathyendranath, S., \& Barlow, R. (2012). The influence of the Indian Ocean Dipole on interannual variations in phytoplankton size structure as revealed by Earth observation. Deep-Sea Research Part II, 77-80, 117-127. https://doi.org/10.1016/j.dsr2.2012.04.009

Brewin, R. J. W., Mélin, F., Sathyendranath, S., Steinmetz, F., Chuprin, A., \& Grant, M. (2014). On the temporal consistency of chlorophyll products derived from three ocean-colour sensors. ISPRS Journal of Photogrammetry, 97, 171-184. https://doi.org/10.1016/j. isprsjprs.2014.08.013

Brewin, R. J. W., Raitsos, D. E., Dall'Olmo, G., Zarokanellos, N., Jackson, T., Racault, M.-F., et al. (2015). Regional ocean-colour chlorophyll algorithms for the Red Sea. Remote Sensing of Environment, 165, 64-85. https://doi.org/10.1016/j.rse.2015.04.024

Brewin, R. J. W., Sathyendranath, S., Hirata, T., Lavender, S., Barciela, R. M., \& Hardman-Mountford, N. J. (2010). A three-component model of phytoplankton size class for the Atlantic Ocean. Ecological Modelling, 168, 437-450. https://doi.org/10.1016/j.rse.2015.07.004

Brewin, R. J. W., Sathyendranath, S., Jackson, T., Barlow, R., Brotas, V., Airs, R., \& Lamont, T. (2015). Influence of light in the mixed layer on the parameters of a three-component model of phytoplankton size structure. Remote Sensing of Environment, 168, 437-450. https:// doi.org/10.1016/j.rse.2015.07.004

Brito, A. C., Sá, C., Brotas, V., Brewin, R. J. W., Silva, T., Vitorino, J., et al. (2015). Effect of phytoplankton size classes on bio-optical properties of phytoplankton in the Western Iberian coast: Application of models. Remote Sensing of Environment, 156, 537-550. https:// doi.org/10.1016/j.rse.2014.10.020

Brown, P. C., \& Cochrane, K. L. (1991). Chlorophyll $a$ distribution in the Southern Benguela: Possible consequences of global warming on phytoplankton and its implications for pelagic fish. South African Journal of Science, 87, 233-242.

Brown, P. C., Painting, S. J., \& Cochrane, K. L. (1991). Estimates of phytoplankton and bacterial biomass and production in the Northern and Southern Benguela ecosystems. South African Journal of Marine Science, 11(1), 537-564. https://doi.org/10.2989/ 025776191784287673

Cermak, J. (2012). Low clouds and fog along the South-Western African coast-Satellite-based retrieval and spatial patterns. Atmospheric Research, 116, 15-21. https://doi.org/10.1016/j.atmosres.2011.02.012

Cermeño, P., Marañón, E., Pérez, V., Serret, P., Fernández, E., \& Castro, C. G. (2006). Phytoplankton size structure and primary production in a highly dynamic coastal ecosystem (Ría de Vigo, NW-Spain): Seasonal and short-time scale variability. Estuarine, Coastal and Shelf Science, 67(1-2), 251-266. https://doi.org/10.1016/j.ecss.2005.11.027

Chaigneau, A., Eldin, G., \& Dewitte, B. (2009). Eddy activity in the four major upwelling systems from satellite altimetry (1992-2007). Progress in Oceanography, 83(1-4), 117-123. https://doi.org/10.1016/j.pocean.2009.07.012 
Chassot, E., Bonhommeau, S., Dulvy, N. K., Mélin, F., Watson, R., Gascuel, D., \& Le Pape, O. (2010). Global marine primary production constrains fisheries catches. Ecology Letters, 13(4), 495-505. https://doi.org/10.1111/j.1461-0248.2010.01443.x

Chavez, F. P., Messié, M., \& Pennington, J. T. (2011). Marine primary production in relation to climate variability and change. Annual Review of Marine Science, 3(1), 227-260. https://doi.org/10.1146/annurev.marine.010908.163917

Claustre, H., Antoine, D., Boehme, L., Boss, E., D'Ortenzio, F., Fanton D'Andon, O., et al. (2010). Guidelines towards an integrated ocean observation system for ecosystems and biogeochemical cycles. In J. Hall, D. E. Harrison, \& D. Stammer (Eds.), Proceedings of OceanObs'09: Sustained ocean observations and information for society (Vol. 1, p. 14). Venice, Italy, 21-25 September 2009: ESA publication WPP-306. https://doi.org/10.5270/OceanObs09.pp.14

de Souza, A. G. Q., Kerr, R., \& de Azevedo, J. L. L. (2018). On the influence of subtropical mode water on the South Atlantic Ocean. Journal of Marine Systems, 185, 13-24. https://doi.org/10.1016/j.jmarsys.2018.04.006

Demarcq, H. (2009). Trends in primary production, sea surface temperature and wind in upwelling systems (1998-2007). Progress in Oceanography, 83(1-4), 376-385. https://doi.org/10.1016/j.pocean.2009.07.022

Demarcq, H., Barlow, R., \& Hutchings, L. (2007). Application of a chlorophyll index derived from satellite data to investigate the variability of phytoplankton in the Benguela ecosystem. African Journal of Marine Science, 29(2), 271-282. https://doi.org/10.2989/ AJMS.2007.29.2.11.194

Demarcq, H., Barlow, R. G., \& Shillington, F. A. (2003). Climatology and variability of sea surface temperature and surface chlorophyll in the Benguela and Agulhas ecosystems as observed by satellite imagery. African Journal of Marine Science, 25(1), 363-372. https://doi. org/10.2989/18142320309504022

Demarcq, H., Reygondeau, G., Alvain, S., \& Vantrepotte, V. (2012). Monitoring marine phytoplankton from space. Remote Sensing of Environment, 117, 211-222. https://doi.org/10.1016/j.rse.2011.09.019

Devred, E., Sathyendranath, S., Stuart, V., \& Platt, T. (2011). A three component classification of phytoplankton absorption spectra: Applications of ocean-colour data. Remote Sensing of Environment, 115(9), 2255-2266. https://doi.org/10.1016/j.rse.2011.04.025

Djavidnia, S., Mélin, F., \& Hoepffner, N. (2010). Comparison of global ocean colour data records. Ocean Science, 6(1), 61-76. https://doi. org/10.5194/os-6-61-2010

Doney, S. C. (2006). Oceanography: Plankton in a warmer world. Nature, 444(7120), 695-696. https://doi.org/10.1038/444695a

Duncombe Rae, C. M., Boyd, A. J., \& Crawford, R. J. M. (1992). "Predation" of anchovy by an Agulhas ring: A possible contributory cause of the very poor year-class of 1989. South African Journal of Marine Science, 12(1), 167-173. https://doi.org/10.2989/02577619209504700

Duncombe Rae, C. M., Shillington, F. A., Agenbag, J. J., Taunton-Clark, J., \& Gründlingh, M. L. (1992). An Agulhas ring in the South Atlantic Ocean and its interaction with the Benguela upwelling frontal system. Deep Sea Research, 39(11-12), 2009-2027. https://doi.org/ 10.1016/0198-0149(92)90011-H

Falkowski, P. G., Ziemann, D., Kolber, Z., \& Bienfang, P. K. (1991). Role of eddy pumping in enhancing primary production in the ocean Nature, 352(6330), 55-58. https://doi.org/10.1038/352055a0

Feng, L., \& Hu, C. (2016). Comparison of valid ocean observations between MODIS Terra and Aqua over the global oceans. IEEE Geoscience and Remote, 54(3), 1575-1585. https://doi.org/10.1109/TGRS.2015.2483500

Field, C. B., Behrenfeld, M. J., Randerson, J. T., \& Falkowski, P. (1998). Primary production of the biosphere: Integrating terrestrial and oceanic components. Science, 281(5374), 237-240. https://doi.org/10.1126/science.281.5374.237

Florenchie, P., Reason, C. J. C., Lutjeharms, J. R. E., Rouault, M., Roy, C., \& Masson, S. (2004). Evolution of interannual warm and cold events in the Southeast Atlantic Ocean. Journal of Climate, 17(12), 2318-2334. https://doi.org/10.1175/1520-0442(2004)017<2318: EOIWAC $>2.0 . \mathrm{CO} ; 2$

Gaube, P., Chelton, D. B., Samelson, R. M., Schlax, M. G., \& O'Neill, L. W. (2015). Satellite observations of mesoscale eddy-induced Ekman pumping. Journal of Physical Oceanography, 45(1), 104-132. https://doi.org/10.1175/JPO-D-14-0032.1

Gordon, H. R., \& Wang, M. (1994). Retrieval of water-leaving radiance and aerosol optical thickness over the oceans with SeaWiFS: A preliminary algorithm. Applied Optics, 33(3), 443-452. https://doi.org/10.1364/AO.33.000443

Grant, M., Jackson, T., Chuprin, A., Sathyendranath, S., Zühlke, M., Dingle, J., et al. (2017). Ocean colour climate change initiative (OC_CCI)—Phase two. Product User Guide. Plymouth Marine Laboratory. http://www.esa-oceancolour-cci.org/

Gregg, W. W., Casey, N. W., \& McClain, C. R. (2005). Recent trends in global ocean chlorophyll. Geophysical Research Letters, 32 , L03606. https://doi.org/10.1029/2004GL021808

Gruber, N., Lachkar, Z., Frenzel, H., Marchesiello, P., Münnich, M., McWilliams, J. C., et al. (2011). Eddy-induced reduction of biological production in eastern boundary upwelling systems. Nature Geoscience, 4(11), 787-792. https://doi.org/10.1038/ngeo1273

Hall, C., \& Lutjeharms, J. R. E. (2011). Cyclonic eddies identified in the Cape Basin of the South Atlantic Ocean. Journal of Marine Systems, 85(1-2), 1-10. https://doi.org/10.1016/j.jmarsys.2010.10.003

Hammond, M. L., Beaulieu, C., Sahu, S. K., \& Henson, S. A. (2017). Assessing trends and uncertainties in satellite-era ocean chlorophyl using space-time modelling. Global Biogeochemical Cycles, 31, 1103-1117. https://doi.org/10.1002/2016GB005600

Henson, S., Cole, H., Beaulieu, C., \& Yool, A. (2013). The impact of global warming on seasonality of ocean primary production. Biogeosciences, 10(6), 4357-4369. https://doi.org/10.5194/bg-10-4357-2013

Henson, S. A., Sarmiento, J. L., Dunne, J. P., Bopp, L., Lima, I., Doney, S. C., et al. (2010). Detection of anthropogenic climate change in satellite records of ocean chlorophyll and productivity. Biogeosciences, 7(2), 621-640. https://doi.org/10.5194/bg-7-621-2010

Hernández-Carrasco, I., Rossi, V., Hernández-García, E., Garçon, V., \& López, C. (2014). The reduction of plankton biomass induced by mesoscale stirring: A modelling study in the Benguela upwelling. Deep-Sea Research Part I, 83, 65-80. https://doi.org/10.1016/j. dsr.2013.09.003

Hirata, T., Hardman-Mountford, N. J., Barlow, R., Lamont, T., Brewin, R., Smyth, T., \& Aiken, J. (2009). An inherent optical property approach to the estimation of size-specific photosynthetic rates in eastern boundary upwelling zones from satellite ocean colour: An initial assessment. Progress in Oceanography, 83(1-4), 393-397. https://doi.org/10.1016/j.pocean.2009.07.019

Huggett, J. A., Lamont, T., Coetzee, J. C., Verheye, H. M. (2016). Long-term declines in southern Benguela zooplankton during summer: Bottom-up or top-down forcing? Poster presented at the Benguela Symposium 2016: Opportunity, Challenge, Change, Cape Town, South Africa, November 2016. https://doi.org/10.13140/RG.2.2.36694.65601

Huggett, J. A., Verheye, H., Escribano, R., \& Fairweather, T. (2009). Copepod biomass, size composition and production in the Southern Benguela: Spatio-temporal patterns of variation, and comparison with other eastern boundary upwelling systems. Progress in Oceanography, 83(1-4), 197-207. https://doi.org/10.1016/j.pocean.2009.07.048

Hutchings, L., Jarre, A., Lamont, T., van den Berg, M., \& Kirkman, S. P. (2012). St Helena Bay (southern Benguela) then and now: Muted climate signals, large human impact. African Journal of Marine Science, 34(4), 559-583. https://doi.org/10.2989/ 1814232X.2012.689672 
Hutchings, L., van der Lingen, C. D., Shannon, L. J., Crawford, R. J. M., Verheye, H. M. S., Bartholomae, C. H., et al. (2009). The Benguela current: An ecosystem of four components. Progress in Oceanography, 83(1-4), 15-32. https://doi.org/10.1016/j.pocean.2009.07.046

Hutchings, L., Verheye, H. M., Huggett, J. A., Demarcq, H., Cloete, R., Barlow, R. G., et al. (2006). Variability of plankton with reference to fish variability in the Benguela current large marine ecosystem-An overview. In V. Shannon, G. Hempel, P. Malanotte-Rizzoli, C. Moloney, \& J. Woods (Eds.), Benguela: Predicting a large marine ecosystem, large marine ecosystems series14 (pp. 91-124). Amsterdam: Elsevier. https://doi.org/10.1016/S1570-0461(06)80011-X

IOCCG (2014). In S. Sathyendranath (Ed.), Phytoplankton functional types from space (Vol. 15). Dartmouth, Canada: Reports of the International Ocean-Colour Coordinating Group.

IPCC (2014). Climate change 2014: Synthesis report. In Core Writing Team, R. K. Pachauri, \& L. A. Meyer (Eds.), Contribution of Working Groups, I, II, and III to the Fifth Assessment Report of the Intergovernmental Panel on Climate Change (p. 151). Geneva, Switzerland: IPCC.

Jarre, A., Hutchings, L., Kirkman, S. P., Kreiner, A., Tchipalanga, P. C. M., Kainge, P., et al. (2015). Synthesis: Climate effects on biodiversity, abundance and distribution of marine organisms in the Benguela. Fisheries Oceanography, 24(S1), 122-149. https://doi.org/ 10.1111/fog.12086

Kanamitsu, M., Ebisuzaki, W., Woollen, J., Yang, S.-K., Hnilo, J. J., Fiorino, M., \& Potter, G. L. (2002). NCEP-DOE AMIP-II reanalysis (R2). Bulletin of the American Meteorological Society, 83(11), 1631-1644. https://doi.org/10.1175/BAMS-83-11-1631

Karstensen, J., \& Quadfasel, D. (2002). Formation of Southern Hemisphere thermocline waters: Water mass conversion and subduction. Journal of Physical Oceanography, 32(11), 3020-3038. https://doi.org/10.1175/1520-0485(2002)032<3020:FOSHTW>2.0.CO;2

Kirkman, S. P., Blamey, L., Lamont, T., Field, J. F., Bianchi, G., Huggett, J. A., et al. (2016). Spatial characterisation of the Benguela ecosystem for ecosystem-based management. African Journal of Marine Science, 38(1), 7-22. https://doi.org/10.2989/ 1814232X.2015.1125390

Kudela, R. M., Garfield, N., \& Bruland, K. W. (2006). Bio-optical signatures and biogeochemistry from intense upwelling and relaxation in coastal California. Deep-Sea Research Part II, 53, 2999-3022. https://doi.org/10.1016/j.dsr2.2006.07.010

Lachkar, Z., \& Gruber, N. (2012). A comparative study of biological production in eastern boundary upwelling systems using an artificial neural network. Biogeosciences, 9(1), 293-308. https://doi.org/10.5194/bg-9-293-2012

Lamont, T., Barlow, R. G., \& Brewin, R. J. W. (2018). Variations in remotely-sensed phytoplankton size structure of a cyclonic eddy in the Southwest Indian Ocean. Remote Sensing, 10(7), 1143. https://doi.org/10.3390/rs10071143

Lamont, T., Barlow, R. G., Brewin, R. J. W. (2019a). Northern Benguela shelf and open ocean seasonal mean chlorophyll $a$ timeseries Department of Environmental Affairs. https://doi.org/10.15493/DEA.MIMS.10000001

Lamont, T., Barlow, R. G., Brewin, R. J. W. (2019b). Southern Benguela shelf and open ocean seasonal mean chlorophyll $a$ timeseries. Department of Environmental Affairs. https://doi.org/10.15493/DEA.MIMS.10000002

Lamont, T., Barlow, R. G., Brewin, R. J. W. (2019c). Agulhas Bank shelf and open ocean seasonal mean chlorophyll $a$ timeseries. Department of Environmental Affairs. https://doi.org/10.15493/DEA.MIMS.10000003

Lamont, T., Barlow, R. G., Brewin, R. J. W. (2019d). Northern Benguela shelf and open ocean seasonal mean microphytoplankton proportion timeseries. Department of Environmental Affairs. https://doi.org/10.15493/DEA.MIMS.10000004

Lamont, T., Barlow, R. G., Brewin, R. J. W. (2019e). Southern Benguela shelf and open ocean seasonal mean microphytoplankton proportion timeseries. Department of Environmental Affairs. https://doi.org/10.15493/DEA.MIMS.10000007

Lamont, T., Barlow, R. G., Brewin, R. J. W. (2019f). Agulhas Bank shelf and open ocean seasonal mean microphytoplankton proportion timeseries. Department of Environmental Affairs. https://doi.org/10.15493/DEA.MIMS.10000010

Lamont, T., Barlow, R. G., Brewin, R. J. W. (2019g). Northern Benguela shelf and open ocean seasonal mean nanophytoplankton proportion timeseries. Department of Environmental Affairs. https://doi.org/10.15493/DEA.MIMS.10000005

Lamont, T., Barlow, R. G., Brewin, R. J. W. (2019h). Southern Benguela shelf and open ocean seasonal mean nanophytoplankton proportion timeseries. Department of Environmental Affairs. https://doi.org/10.15493/DEA.MIMS.10000008

Lamont, T., Barlow, R. G., Brewin, R. J. W. (2019i). Agulhas Bank shelf and open ocean seasonal mean nanophytoplankton proportion timeseries. Department of Environmental Affairs. https://doi.org/10.15493/DEA.MIMS.10000011

Lamont, T., Barlow, R. G., Brewin, R. J. W. (2019j). Northern Benguela shelf and open ocean seasonal mean picophytoplankton proportion timeseries. Department of Environmental Affairs. https://doi.org/10.15493/DEA.MIMS.10000006

Lamont, T., Barlow, R. G., Brewin, R. J. W. (2019k). Southern Benguela shelf and open ocean seasonal mean picophytoplankton proportion timeseries. Department of Environmental Affairs. https://doi.org/10.15493/DEA.MIMS.10000009

Lamont, T., Barlow, R. G., Brewin, R. J. W. (2019l). Agulhas Bank shelf and open ocean seasonal mean picophytoplankton proportion timeseries. Department of Environmental Affairs. https://doi.org/10.15493/DEA.MIMS.10000012

Lamont, T., Barlow, R. G., Brewin, R. J. W. (2019m). Northern Benguela shelf total cumulative upwelling index. Department of Environmental Affairs. https://doi.org/10.15493/DEA.MIMS.10000013

Lamont, T., Barlow, R. G., Brewin, R. J. W. (2019n). Southern Benguela shelf total cumulative upwelling index. Department of Environmental Affairs. https://doi.org/10.15493/DEA.MIMS.10000014

Lamont, T., Barlow, R. G., Brewin, R. J. W. (2019o). Agulhas Bank shelf total cumulative upwelling index. Department of Environmental Affairs. https://doi.org/10.15493/DEA.MIMS.10000015

Lamont, T., Brewin, R. J. W., \& Barlow, R. G. (2018). Seasonal variation in remotely-sensed phytoplankton size structure around southern Africa. Remote Sensing of Environment, 204, 617-631. https://doi.org/10.1016/j.rse.2017.09.038

Lamont, T., García-Reyes, M., Bograd, S. J., van der Lingen, C. D., \& Sydeman, W. J. (2018). Upwelling indices for comparative ecosystem studies: Variability in the Benguela Upwelling System. Journal of Marine Systems, 188, 3-16. https://doi.org/10.1016/j. jmarsys.2017.05.007

Lett, C., Veitch, J., van der Lingen, C., \& Hutchings, L. (2007). Assessment of an environmental barrier to transport of ichthyoplankton from the Southern to the Northern Benguela ecosystem. Marine Ecology Progress Series, 347, 247-259. https://doi.org/10.3354/ meps06982

Lévy, M., Ferrari, R., Franks, P. J. S., Martin, A. P., \& Rivière, P. (2012). Bringing physics to life at the submesoscale. Geophysical Research Letters, 39, L14602. https://doi.org/10.1029/2012GL052756

Louw, D. C., van der Plas, A. K., Mohrholz, V., Wasmund, N., Junker, T., \& Eggert, A. (2016). Seasonal and interannual phytoplankton dynamics and forcing mechanisms in the Northern Benguela Upwelling System. Journal of Marine Systems, 157, 124-134. https://doi. org/10.1016/j.jmarsys.2016.01.009

Lutjeharms, J. R. E., Shillington, F. A., \& Duncombe Rae, C. M. (1991). Observations of extreme upwelling filaments in the Southeast Atlantic Ocean. Science, 253(5021), 774-776. https://doi.org/10.1126/science.253.5021.774 
Mahadevan, A. (2016). The impact of sub-mesoscale physics on primary productivity of plankton. Annual Review of Marine Science, 8(1), 161-184. https://doi.org/10.1146/annurev-marine-010814-015912

Maritorena, S., \& Siegel, D. A. (2005). Consistent merging of satellite ocean color data sets using a bio-optical model. Remote Sensing of Environment, 94(4), 429-440. https://doi.org/10.1016/j.rse.2004.08.014

Marrari, M., Piola, A. R., \& Valla, D. (2017). Variability and 20-year trends in satellite-derived surface chlorophyll concentrations in large marine ecosystems around South and Western Central America. Frontiers in Marine Science, 4, 372. https://doi.org/10.3389/ fmars.2017.00372

Martinez, E., Antoine, D., D'Ortenzio, F., \& Gentili, B. (2009). Climate-driven basin-scale decadal oscillations of oceanic phytoplankton. Science, 326(5957), 1253-1256. https://doi.org/10.1126/science.1177012

Mélin, F., \& Sclep, G. (2015). Band shifting for ocean color multi-spectral reflectance data. Optics Express, 23(3), 2262-2279. https://doi.org/ 10.1364/OE.23.002262

Mélin, F., Vantrepotte, V., Chuprin, A., Grant, M., Jackson, T., \& Sathyendranath, S. (2017). Assessing the fitness-for-purpose of satellite multi-mission ocean color climate data records: A protocol applied to OC-CCI chlorophyll- $a$ data. Remote Sensing of Environment, 203, 139-151. https://doi.org/10.1016/j.rse.2017.03.039

Morel, A., \& Prieur, L. (1977). Analysis of variations in ocean color. Limnology and Oceanography, 22(4), 709-722. https://doi.org/10.4319/ 10.1977.22.4.0709

Moriceau, B., Iverson, M. H., Gallinari, M., Evertsen, A.-J. O., Le Goff, M., Beker, B., et al. (2018). Copepods boost the production but reduce the carbon export efficiency by diatoms. Frontiers in Marine Science, 5, 82. https://doi.org/10.3389/fmars.2018.00082

Muller-Karger, F. E., Piola, A., Verheye, H. M., O'Brien, T. D., \& Lorenzoni, L. (2017). South Atlantic Ocean. In T. D. O'Brien, L. Lorenzoni, $\mathrm{K}$. Isensee, \& L. Valdés (Eds.), What are marine ecological time series telling us about the ocean? A status report IOC-UNESCO, IOC technical series (Vol. 129, pp. 83-96). http://unesdoc.unesco.org/images/0024/002470/247014E.pdf

NASA Goddard Space Flight Center, Ocean Ecology Laboratory, Ocean Biology Processing Group (2018a). Sea-viewing Wide Field-of-view Sensor (SeaWiFS) Chlorophyll Data; 2018 Reprocessing. NASA OB.DAAC, Greenbelt, MD. https://doi.org/10.5067/ORBVIEW-2/ SEAWIFS/L3M/CHL/2018. Accessed on 23/03/2018.

NASA Goddard Space Flight Center, Ocean Ecology Laboratory, Ocean Biology Processing Group (2018b). Moderate-resolution Imaging Spectroradiometer (MODIS) Aqua Chlorophyll Data; 2018 Reprocessing. NASA OB.DAAC, Greenbelt, MD. https://doi.org/10.5067/ AQUA/MODIS/L3M/CHL/2018. Accessed on 23/03/2018.

Ohde, T., \& Dadou, I. (2018). Seasonal and annual variability of coastal sulphur plumes in the Northern Benguela Upwelling System. PLoS One, 13(2), e0192140. https://doi.org/10.1371/journal.pone.0192140

Oschlies, A., \& Garçon, V. (1998). Eddy-induced enhancement of primary production in a model of the North Atlantic Ocean. Nature, 394(6690), 266-269. https://doi.org/10.1038/28373

Pauly, D., \& Christensen, D. B. (1995). Primary production required to sustain global fisheries. Nature, 374(6519), 255-257. https://doi.org/ $10.1038 / 374255 \mathrm{a} 0$

Pohl, B., Fauchereau, N., Reason, C. J. C., \& Rouault, M. (2010). Relationships between the Antarctic Oscillation, the Madden-Julian Oscillation, and ENSO, and consequences for rainfall analysis. Journal of Climate, 23(2), 238-254. https://doi.org/10.1175/ 2009JCLI2443.1

Polovina, J. J., Howell, E. A., \& Abecassis, M. (2008). Ocean's least productive waters are expanding. Geophysical Research Letters, 35, L03618. https://doi.org/10.1029/2007GL031745

Probyn, T. A. (1992). The inorganic nitrogen nutrition of phytoplankton in the southern Benguela: New production, phytoplankton size and implications for pelagic foodwebs. South African Journal of Marine Science, 12(1), 411-420. https://doi.org/10.2989/ 02577619209504715

Probyn, T. A., Mitchell-Innes, B. A., Brown, P. C., Hutchings, L., \& Carter, R. A. (1994). A review of primary production and related processes on the Agulhas Bank. South African Journal of Science, 90, 166-173.

Quartly, G., \& Srokosz, M. (2004). Eddies in the southern Mozambique Channel. Deep-Sea Research Part II, 51(1-3), 69-83. https://doi.org/ 10.1016/j.dsr2.2003.03.001

R Core Team (2018). R: A language and environment for statistical computing. Vienna, Austria: R Foundation for Statistical Computing. https://www.R-project.org/

Raitsos, D. E., Pi, X., Platt, T., Racault, M.-F., Brewin, R. J. W., Pradhan, Y., et al. (2015). Monsoon oscillations regulate fertility of the Red Sea. Geophysical Research Letters, 42, 855-862. https://doi.org/10.1002/2014GL062882

Reason, C. J. C., Florenchie, P., Rouault, M., \& Veitch, J. (2006). Influences of large scale climate modes and Agulhas system variability on the BCLME region. In V. Shannon, G. Hempel, P. Malanotte-Rizzoli, C. Moloney, \& J. Woods (Eds.), Benguela: Predicting a large marine ecosystem, large marine ecosystems series14 (pp. 223-238). Amsterdam: Elsevier. https://doi.org/10.1016/ S1570-0461(06)80015-7

Rossi, V., López, C., Hernández-García, E., Sudre, J., Garçon, V., \& Morel, Y. (2009). Surface mixing and biological activity in the four eastern boundary upwelling systems. Nonlinear Processes in Geophysics, 16(4), 557-568. https://doi.org/10.5194/npg-16-557-2009

Rossi, V., López, C., Sudre, J., Hernández-García, E., \& Garçon, V. (2008). Comparative study of mixing and biological activity of the Benguela and California upwelling systems. Geophysical Research Letters, 35, L11602. https://doi.org/10.1029/2008GL033610

Rouault, M., Florenchie, P., Fauchereau, N., \& Reason, C. J. C. (2003). South East Atlantic warm events and southern African rainfall. Geophysical Research Letters, 30(5), 8009. https://doi.org/10.1029/2002GL014840

Rouault, M., Pohl, B., \& Penven, P. (2010). Coastal oceanic climate change and variability from 1982 to 2009 around South Africa. African Journal of Marine Science, 32(2), 237-246. https://doi.org/10.2989/1814232X.2010.501563

Rubio, A., Blanke, B., Speich, S., Grima, N., \& Roy, C. (2009). Mesoscale activity in the Southern Benguela Upwelling System from satellite altimetry and model data. Progress in Oceanography, 83(1-4), 288-295. https://doi.org/10.1016/j.pocean.2009.07.029

Rubio, A., Caballero, A., Orfila, A., Hernández-Carrasco, I., Ferrer, L., González, M., et al. (2018). Eddy-induced cross-shelf export of high Chl-a coastal waters in the SE Bay of Biscay. Remote Sensing of Environment, 205, 290-304. https://doi.org/10.1016/j. rse.2017.10.037

Rykaczewski, R. R., \& Dunne, J. P. (2010). Enhanced nutrient supply to the California Current Ecosystem with global warming and increased stratification in an Earth system model. Geophysical Research Letters, 37, L21606. https://doi.org/10.1029/2010GL045019

Salt, L. A., van Heuven, S. M. A. C., Claus, M. E., Jones, E. M., \& de Baar, H. J. W. (2015). Rapid acidification of mode and intermediate waters in the southwestern Atlantic Ocean. Biogeosciences, 12(5), 1387-1401. https://doi.org/10.5194/bg-12-1387-2015

Sathyendranath, S., Brewin, R. J. W., Jackson, T., Mélin, F., \& Platt, T. (2017). Ocean-colour products for climate-change studies: What are their ideal characteristics? Remote Sensing of Environment, 203, 125-138. https://doi.org/10.1016/j.rse.2017.04.017 
Shannon, L. V., \& Nelson, G. (1996). The Benguela: Large scale features and processes and system variability. In G. Wefer, W. H. Berger, G. Siedler, \& D. J. Webb (Eds.), The South Atlantic: Present and past circulation (pp. 163-210). Berlin: Springer. https://doi.org/10.1007/9783-642-80353-6 9

Shillington, F. A., Hutchings, L., Probyn, T. A., Waldron, H. N., \& Peterson, W. T. (1992). Filaments and the Benguela frontal zone: Offshore advection or recirculating loops? South African Journal of Marine Science, 12(1), 207-218. https://doi.org/10.2989/ 02577619209504703

Shillington, F. A., Reason, C. J. C., Duncombe Rae, C. M., Florenchie, P., \& Penven, P. (2006). Large scale physical variability of the Benguela current large marine ecosystem (BCLME). In V. Shannon, G. Hempel, P. Malanotte-Rizzoli, C. Moloney, \& J. Woods (Eds.), Benguela: Predicting a large marine ecosystem, large marine ecosystems series14 (pp. 49-70). Amsterdam: Elsevier. https://doi.org/ 10.1016/S1570-0461(06)80009-1

Siegel, D. A., Behrenfeld, M. J., Maritorena, S., McClain, C. R., Antoine, D., Bailey, S. W., et al. (2013). Regional to global assessments of phytoplankton dynamics from the SeaWiFS mission. Remote Sensing of Environment, 135, 77-91. https://doi.org/10.1016/j. rse.2013.03.025

Signorini, S. R., Franz, B. A., \& McClain, C. R. (2015). Chlorophyll variability in the oligotrophic gyres: Mechanisms, seasonality and trends. Frontiers in Marine Science, 2, 1. https://doi.org/10.3389/fmars.2015.00001

Tim, N., Zorita, E., \& Hünicke, B. (2015). Decadal variability and trends of the Benguela Upwelling System simulated in a high-resolution ocean simulation. Ocean Science, 11(3), 483-502. https://doi.org/10.5194/os-11-483-2015

Uitz, J., Claustre, H., Morel, A., \& Hooker, S. B. (2006). Vertical distribution of phytoplankton communities in the open ocean: An assessment based on surface chlorophyll. Journal of Geophysical Research, 111, C08005. https://doi.org/10.1029/2005JC003207

van der Lingen, C. D., Hutchings, L., Lamont, T., \& Pitcher, G. C. (2016). Climate change, dinoflagellate blooms and sardine in the southern Benguela current large marine ecosystem. Environment Development, 17, 230-243. https://doi.org/10.1016/j.envdev.2015.09.004

Vantrepotte, V., \& Mélin, F. (2009). Temporal variability of 10-year global SeaWiFS time-series of phytoplankton chlorophyll $a$ concentration. ICES Journal of Marine Science, 66(7), 1547-1556. https://doi.org/10.1093/icesjms/fsp107

Veitch, J. A., \& Penven, P. (2017). The role of the Agulhas in the Benguela current system: A numerical modelling approach. Journal of Geophysical Research: Oceans, 122, 3375-3393. https://doi.org/10.1002/2016JC012247

Venegas, S. A., Mysak, L. A., \& Straub, D. N. (1998). An interdecadal climate signal in the South Atlantic and its links to other ocean basins. Journal of Geophysical Research, 103, 24 723-24 736. https://doi.org/10.1029/98JC02443

Verheye, H. M. (2000). Decadal-scale trends across several marine trophic levels in the Southern Benguela Upwelling System off South Africa. Ambio, 29(1), 30-34. https://doi.org/10.1579/0044-7447-29.1.30

Verheye, H. M., Kirkman, S., Crawford, R. J. M., \& Huggett, J. A. (2017). State of the oceans and coasts around South Africa 2016 Report Card, Report No. 16, Department of Environmental Affairs, Pretoria, RP358/2017, 33 pp. ISBN: 978-0-621-46011-7.

Verheye, H. M., Lamont, T., Huggett, J. A., Kreiner, A., \& Hampton, I. (2016). Plankton productivity of the Benguela current large marine ecosystem (BCLME). Environment Development, 17, 75-92. https://doi.org/10.1016/j.envdev.2015.07.011

Verheye, H. M., \& Richardson, A. J. (1998). Long-term increase in crustacean zooplankton abundance in the Southern Benguela Upwelling Region (1951-1996): Bottom-up or top-down control? ICES Journal of Marine Sciences, 55(4), 803-807. https://doi.org/10.1006/ jmsc.1998.0387

Verheye, H. M., Richardson, A. J., Hutchings, L., Marska, G., \& Gianakouras, D. (1998). Long-term trends in the abundance and community structure of coastal zooplankton in the Southern Benguela System, 1951-present. South African Journal of Marine Science, 19(1), 317-332. https://doi.org/10.2989/025776198784126728

Vickery, K. J., Eckardt, F. D., \& Bryant, R. G. (2013). A sub-basin scale dust plume source frequency inventory for southern Africa, 20052008. Geophysical Research Letters, 40, 5274-5279. https://doi.org/10.1002/grl.50968

Wang, M. (2006). Aerosol polarization effects on atmospheric correction and aerosol retrievals in ocean color remote sensing. Applied Optics, 45(35), 8951-8963. https://doi.org/10.1364/AO.45.008951

Wang, Y., Zhang, H.-R., Chai, F., \& Yuan, Y. (2018). Impact of mesoscale eddies on chlorophyll variability off the coast of Chile. PLoS One, 13(9), e0203598. https://doi.org/10.1371/journal.pone.0203598

Ward, B. A. (2015). Temperature-correlated changes in phytoplankton community structure are restricted to polar waters. PLoS One, 10(8), e0135581. https://doi.org/10.1371/journal.pone.0135581

Weeks, S. J., Barlow, R., Roy, C., \& Shillington, F. A. (2006). Remotely sensed variability of temperature and chlorophyll in the Southern Benguela: Upwelling frequency and phytoplankton response. African Journal of Marine Science, 28(3-4), 493-509. https://doi.org/ $10.2989 / 18142320609504201$

Werdell, P. J., Bailey, S. W., Franz, B. A., Harding, L. W. Jr., Feldman, G. C., \& McClain, C. R. (2009). Regional and seasonal variability of chlorophyll- $a$ in Chesapeake Bay as observed by SeaWiFS and MODIS-Aqua. Remote Sensing of Environment, 113(6), 1319-1330. https:// doi.org/10.1016/j.rse.2009.02.012

Xui, P., Chai, F., Curchitser, E. N., \& Castruccio, F. S. (2018). Future changes in coastal upwelling ecosystems with global warming: The case of the California Current System. Scientific Reports, 8, 2866. https://doi.org/10.1038/s41598-018-21247-7 